\title{
Review of the genus Agnippe (Lepidoptera: Gelechiidae) in the Palaearctic region
}

\author{
OLEKSIY BIDZILYA ${ }^{1}$ and HouHun LI² \\ ${ }^{1}$ Kiev National Taras Shevchenko University, Zoological Museum, Vladimirskaya str. 64, 01601 MSP Kiev, Ukraine; \\ e-mail: bidzilya@univ.kiev.ua \\ ${ }^{2}$ College of Life Sciences, Nankai University, Tianjin 300071, P.R. China; e-mail: lihouhun@nankai.edu.cn
}

Key words. Lepidoptera, Gelechiidae, Agnippe, Palaearctic Region, systematics, new species, new synonyms, new records

\begin{abstract}
The genus Agnippe Chambers, 1872 in the Palaearctic Region is revised. Sixteen species are recognized as valid. Three new synonyms are established: A. conjugella Caradja, $1920=$ A. haberlandii Amsel, 1961 syn. n., A. lunaki Rebel, $1941=$ A. penicillata Amsel, 1961 syn. n., A. kuznetzovi Lvovsky \& Piskunov, $1989=A$. zhengi Li, 1993 syn. n. Four new species are described: $A$. echinuloides sp. n. (S Ural, Tuva, Transbaikalia, Mongolia), A. turanica sp. n. (Uzbekistan, Kazakhstan), A. deserta sp. n. (Uzbekistan) and $A$. separatella sp. n. (S Iran). Description of all the species and an identification key are presented, accompanied by illustrations of the adults, and male and female genitalia.
\end{abstract}

\section{INTRODUCTION}

The genus Agnippe comprises about 30 species occurring mainly in the Holarctic Region. There are also a few records for the Neotropical Region (Becker, 1984). Nearctic species are listed by Hodges (1983). Later Lee \& Brown (2008) synonymized Evippe Chambers, 1873 with Agnippe Chambers, 1872, refined the definition of the genus and proposed a list of Holarctic species based on new generic combinations. The Palaearctic Agnippe species have not been reviewed in full. Detailed descriptions of two species that occur in Japan are given by Okado (1961), and the Chinese fauna was revised by Li (1993), Wang \& Li (1994), Li \& Zheng (1998) and Li (2002). There are two European species included in the first volume of Gelechiidae of Europe (Huemer \& Karsholt, 1999).

In the course of our study, sixteen Agnippe species were recognized in the Palaearctic Region, four of which are described as new; three new synonyms are established. All the species are described or redescribed, along with illustrations of the adults and the male and female genitalia of each taxon.

\section{MATERIAL AND METHODS}

The present study is based primarily on material in the following collections: BMNH - Natural History Museum, London, UK; MGAB - Museum of Natural History "Grigore Antipa", Bucharest, Romania; NKUM - Nankai University, Tianjin, China; RMNH - Rijksmuseum van Natuurlijke Historie, Leiden, Netherlands; SMNK - Staatliches Museum für Naturkunde, Karlsruhe, Germany; ZIN - Zoological Institute, Russian Academy of Sciences, Sankt-Petersburg, Russia; ZMKU - Zoological Museum, Kiev National Taras Shevchenko University, Kiev, Ukraine; ZMUC - Zoological Museum, University of Copenhagen, Copenhagen, Denmark; ZSM - Zoologische Staatssammlung Munich, Germany. The types of 12 nominal species have been examined.
Male and female genitalia were prepared using the unrolling technique as described by Pitkin (1986) and Huemer (1988). Biological data were mainly extracted from bibliographic sources. For some species, personal observations and label data were also available.

The distribution of species was established primarily from the material examined and supplemented by data in the literature. The "Material" is arranged in geographical order from northwest to south-east and countries referred to by their current names.

\section{RESULTS}

\section{Check-list of Palaearctic Agnippe}

A. lunaki (Rebel, 1941)

$=$ A. penicillata Amsel, 1961 syn. $\mathrm{n}$.

A. syrictis (Meyrick, 1936)

A. novisyrictis (Li, 1993)

A. yongdengensis $(\mathrm{Li}, 1993)$

A. echinulata (Li, 1993)

A. dichotoma (Li, 1993)

A. echinuloides sp. $\mathrm{n}$.

A. turanica sp. n.

A. albidorsella (Snellen, 1884)

A. zhouzhiensis (Li, 1993)

A. kuznetzovi (Lvovsky \& Piskunov, 1989)

$=A$. zhengi Wang \& Li, 1994 syn. $\mathrm{n}$.

A. deserta sp. $\mathrm{n}$.

A. conjugella (Caradja, 1920)

$=A$. haberlandi Amsel, 1961 syn. $\mathrm{n}$.

A. pseudolella (Christoph, 1888)

$=$ A. cephalella Caradja, 1920

A. miniscula (Li, 1993)

A. separatella $\mathrm{sp} . \mathrm{n}$.

\section{Genus Agnippe Chambers, 1872}

Agnippe Chambers, 1872: 194. Type-species: Agnippe biscolorella Chambers, 1872, by subsequent designation (Meyrick, 1925).

Aganippe Chambers, 1880: 198. Misspelling of Agnippe Chambers, 1872. 
Phaetusa Chambers, 1875: 105. Preoccupied by Phaetusa Wagler, 1832 (Aves).

Evippe Chambers, 1873: 185. Type-species: Evippe prunifoliella Chambers, 1873, by monotypy. [Synonymized by Lee \& Brown, 2008].

Tholerostola Meyrick, 1917: 40. Type-species: Tholerostola omphalopa Meyrick, 1917, by monotypy. [Synonymized by Clarke, 1955].

Diagnosis. Adult. Small or average-sized, length of forewing 4.0-6.0 mm. Head white, pale or light brown, smoothly scaled, ocellus absent; labial palpus long and slender, protruding far over head, white, light brown to cream. Scapus black or brown. Thorax and tegula usually white or pale. Forewing white or pale with strongly developed dark or brown patches, forming basal fascia and two connected or separated spots under costal margin; in some species forewing divided by wavy black line into grey-black costal and creamy-white posterior parts. Hindwing trapezoid, termen distinctly excavated.

Venation. On forewing, Sc reaching to about middle of costa; $\mathrm{R}_{1}$ from half of cell, but this vein sometimes absent in male (Lee \& Brown, 2008), $\mathrm{R}_{2}$ from three-quarters of cell, $\mathrm{R}_{3}$ just from corner of cell; $\mathrm{R}_{4}$ and $\mathrm{R}_{5}$ on common stalk, from corner of cell to costa just before apex, $\mathrm{R}_{5}$ and $\mathrm{M}_{1}$ stalked, $\mathrm{M}_{1}-\mathrm{M}_{3}$ and $\mathrm{Cu}_{1}-\mathrm{Cu}_{2}$ to termen, $\mathrm{M}_{2}-\mathrm{M}_{3}$ on common stalk, from tornus of cell, $\mathrm{CuA}_{1}-\mathrm{CuA}_{2}$ distinctly separated basely, $\mathrm{CuP}$ absent, $1 \mathrm{~A}+2 \mathrm{~A}$ forked at base. On hindwing $\mathrm{R}_{1}$ forming an anastamosis with $\mathrm{M}_{1}$ near base, Rs and $\mathrm{M}_{1}$ with long common stalk, $\mathrm{R}_{5}$ to costa near apex, $\mathrm{M}_{1}-\mathrm{M}_{3}$ to termen, $\mathrm{M}_{3}$ from common point with $\mathrm{CuA} \mathrm{A}_{1}$ or separated, $1 \mathrm{~A}-2 \mathrm{~A}$ indistinct.

Frenulum of female consisting of two acanthae, retinaculum a row of raised scales at base of Sc and along R. Frenulum of male simple, retinaculum a membranous hook under Sc near base.

Male sternite and tergite VIII divided laterally; tergite VIII normally weakly sclerotized, width somewhat exceeding length, rounded apically, usually with broad anterior emargination; sternite VIII normally elongate, anterior margin broadly emarginated, varying in shape: usually constricted medially, with wide basal half and narrow distal part, rounded apically, in some species tongue-shaped. Female segment VII slightly longer than other abdominal segments. Sternite II of both sexes with paired venula.

Male genitalia. Uncus long and narrow, slender, nearly parallel-sided, straight or gradually curved, apex with small medial incision. Gnathos gradually curved, consisting of ventral and dorsal parts: ventral part flat, with trifid apex, nearly as long as length of uncus; dorsal part sickle-shaped, with short narrow process at two-thirds, apex pointed. Tegumen about twice as long as broad, anterior margin with deep triangular emargination. Valva divided into cucullus and sacculus. Cucullus long and narrow, digitate, straight or weakly constricted in middle, apex usually broad, round, with small apical tooth, normally set with long hair-like setae on distal portion, shorter or extending to top of uncus. Sacculus short, digitate or rounded. Vinculum short and narrow, juxta fused with vinculum and represented by small short medial lobes on its posterior margin. Saccus long and narrow, usually parallel-sided or weakly narrowed apically, apex rounded or slightly pointed. Aedeagus stout, straight, about as long as length of tegumen, distal portion with strongly sclerotized oblique filament, with apical tooth; vesica usually with sclerotized plate and needle-like cornuti.

Female genitalia. Papilla analis moderately short, sub-oval, densely covered with short setae. Apophyses anteriores short, from half to one-third length of apophyses posteriores, straight or weakly curved. Segment VIII weakly sclerotized, usually trapezoid, slightly broader than long, but sometimes elongate; anterior margin strongly sclerotized. Ductus bursae very short, membranous; antrum strongly sclerotized, funnel-shaped, tubular or nearly triangular, usually shorter, but sometimes longer than apophyses anteriores. Corpus bursae rounded, distinct accessory bursae with numerous spines or teeth inside usually well developed; signum a sub-triangular, sub-trapezoid, cap-shaped or elongate sub-rhomboid plate usually with transverse ridge, its apical portion strongly sclerotized and finely serrated, anterior margin irregularly dentate.

Relationships. Agnippe is a very homogenous genus, clearly defined by the apically trifid uncus, the strongly developed dorsal part of gnathos, the vesica with sclerotized plate and cornuti in the male genitalia; and by the strongly developed accessory bursae with numerous spines or teeth inside in the female genitalia. Agnippe is rather isolated within Gelechiidae due to a number of unique genitalic characters. It was considered a member of the tribe Litini (=Teleiodini) by Huemer \& Karsholt (1999). Lee \& Brown (2008) placed Agnippe and closely related monotypic genus Glauce Chambers, 1875 in Litini, mentioning that both genera differ from other members of this tribe by the absence of raised scales on forewing. In contrast, Ponomarenko (2005) placed Agnippe in the tribe Gelechiini based on the morphology of male genitalia, and regarded the dorsal part of gnathos as a strongly developed culcitula, which is one of the diagnostic characters of Gelechiini.

Our study of Agnippe indicates that this genus should be included in the tribe Gelechiini rather than Litini. The former is characterized by the valvae, juxta and vinculum having a tendency to fuse, and the usually reduced gnathos and aedeagus normally strongly connected with the vinculum. Moreover, most members of Litini have well developed glandiductors in the male genitalia (Ponomarenko, 2005), which are absent in Agnippe. On the other hand, strongly developed accessory bursae in the female genitalia is characteristic of some genera of Litini, for example Parastenolechia Kanazwa, 1985 and Parachronistis Meyrick, 1925. The male genitalia of Agnippe share such characters with Gelechiini as strongly developed culcitula and valva, divided into long strongly developed sacculus and short cucullus. So the view of Ponomarenko is accepted here and Agnippe tentatively considered as a member of Gelechiini. It should be noted that the diagnosis of both tribes remains rather uncertain and the sys- 
tematic position of Agnippe and Glauce needs to be clarified in future.

Biology. Pinus sp. (Pinaceae), Lespedeza sp., Alhagi sparsifolia Shaparenko and Pseudosophora alopecuroides L. (Fabaceae) are known host-plants for four Palaearctic species (Okada, 1961; Lvovsky \& Piskunov, 1989; Falkovitsh \& Bidzilya, 2003). Quercus spp. (Fagaceae), Lezpedeza sp., Gleditsia sp. (Fabaceae), Cercocarpus ledifolius Nutt and Prunus spp. (Rosaceae) are recorded as a host-plants for the Nearctic species (Lee \& Brown, 2008). Larvae are described for A albidorsella and $A$. syrictis (Okada, 1961). Pupa is described by Mosher (1916). Adults fly from April to September.

Distribution. Sixteen species are known from the Palaearctic and ten from the Nearctic (Lee \& Brown, 2008), five species are recorded for the Neotropical region (Becker, 1984). In the Palaearctic region, Agnippe species are distributed from South-East Europe to Japan, East China and Korea, and most species occur in steppe, desert and semi-desert areas of Central Asia.

Remarks. Most species of Agnippe may be distinguished superficially, except $A$. albidorsella $-A$. zhouzhiensis and A. novisyrictis - A. yongdengensis, but correct determination must be supported by the study of genitalia of both sexes. In some cases, the shape of male abdominal segment VIII may be used as an additional diagnostic character.

\section{Key to species of Agnippe}

1 Forewing mainly blackish-brown with narrow cream zone along posterior margin. . . . . . . . . . . . 2

- Forewing blackish-brown with well developed broad white pattern.

2 Posterior margin of forewing dark, grey with distinct brown medial spot; cucullus weakly broadened medially, slightly curved inwards and rounded apically; sacculus short and narrow, weakly pointed, sub-triangular; antrum far exceeding the length of apophyses anteriores......... 3

- Posterior margin of forewing light, whitish-cream, brown medial spot not developed; cucullus nearly straight or medially narrowed, apex broad, sub-triangular or rounded; sacculus broadly rounded; antrum shorter than apophyses

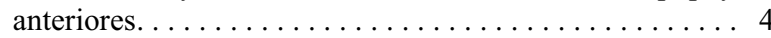

3 Anterior margin of tergite VIII with distinct medial emargination. ....................... novisyrictis

- Anterior margin of tergite VIII nearly straight.

....................... youngdengensi.

4 Cucullus distinctly broader apically, sub-triangular, constricted medially; apex of gnathos relatively narrow, with processes positioned close to one another....... A. syrictis

- Cucullus weakly broader apically, rounded, nearly straight; apex of gnathos broader, with broadly divided processes....

5 Costal margin of forewing white with one dark medial subtriangular spot; saccus long, cucullus short, uncus very short and broad. ................... A. separatella $\mathrm{sp.}$.

- Costal margin of forewing with strongly developed blackish pattern. . . . . . . . . . . . . . . . . . . . . . 6

6 Forewing with broad black medial transverse fascia..... 7

- Forewing without black medial transverse fascia...... 8

7 Antrum elongate, funnel-shaped; signum sub-rhomboid. . . . A. albidorsella
- Antrum short and broad, rounded anteriorely; signum sub-

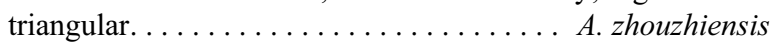

8 Forewing with uninterrupted black zone from one- to threequarters along length. . . . . . . . . . . . . . . 9

- Forewing with black zone from one- to three-quarters along length interrupted by white. ............... 12

9 White sub-apical fascia not interrupted, white pattern on posterior margin rounded............ A. turanica sp. n.

- White sub-apical fascia divided into two spots, white pattern on posterior margin triangular. . . . . . . . . . 10

10 Cucullus bifurcated apically........... A. dichotoma

- Cucullus not bifurcated apically............... 11

11 Cucullus broad, distinctly broader apically, sacculus apically pointed, gnathos broad........ A. echinuloides sp. n.

- Cucullus slender, weakly broader apically, sacculus rounded apically, gnathos narrow............... A. echinulata

12 Black sub-apical zone with medial white spot, but not interrupted posteriorly. ................... 13

- Black sub-apical zone divided into two spots........ 15

13 White medial spot elongate. . . . . . . . . . . . . . 14 White medial spot rounded. ............ conjugella

14 White medial spot very long, usually not interrupted by brownish fascia, connected with sub-apical white patch; cucullus relatively short, straight. ......A. deserta sp. n. White medial spot shorter, not connected with sub-apical white patch; cucullus relatively long, weakly broader medially. ........................... kuznetzovi

15 Spots black, usually closely connected; genitalic capsula elongate; accessory bursae with large sub-triangular teeth, signum rounded. . . . . ............ pseudolella

- Spots brown, clearly separated; genitalic capsula relatively broad; accessory bursae with small needle-shaped teeth, signum ellipsoid. ................. A. miniscula

\section{Review of species}

\section{Agnippe lunaki (Rebel, 1941)}

Stenolechia lunaki Rebel, 1941. Lectotype ô, Macedonia, labelled "Lectotype", "Macedonia Ochrid 12.-24.vi.39 leg. R.

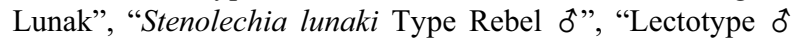
Stenolechia lunaki Rebel det L.M. Pitkin, 1987" (BMNH) [not examined].

Evippe lunaki (Rebel, 1941): Huemer \& Karsholt, 1999.

Agnippe lunaki (Rebel, 1941): Lee \& Brown, 2008.

Evippe penicillata Amsel, 1961, syn. n. Holotype ô, labelled "Syria sept., Taurus, Marasch, 700-900 m, vi.1929, coll. Osthelder" (ZSM) (gen. prep. 458, 468c, K. Sattler) [examined].

Agnippe penicillata (Amsel, 1961): Lee \& Brown, 2008.

Type material. Holotype of penicillata as above.

Additional material. 2 $\%$, Macedonia, Ohrid, vi.1939, R. Wolfschäger leg. (gen. prep. 165/07) (ZSM); 10, Turkey, Asia Minor, NW End of Beysehir Lake, 14-16.vi.1966, J. Klimesch leg. (gen. prep. 164/07) (ZSM); 10 , Greece, Is. Crete, Assites, 550 m, 5.vii.1962, H. Reisser leg. (ZSM).

Diagnosis. Agnippe lunaki resembles A. syrictis externally and in its genitalia. For separation see the diagnosis under the latter species.

Adult (Figs 1, 2). Wingspan 7.8-9.0 mm. Head and thorax yellowish-white. Labial palpus with outer surface of segment 2 black, apical one-third white, inner surface white; segment 3 white with black apex. Scapus black, other antennal segments white, ringed with black basally. Tegula black. Costal part of forewing black, posterior part yellow-cream, costal margin with small yellow-white 

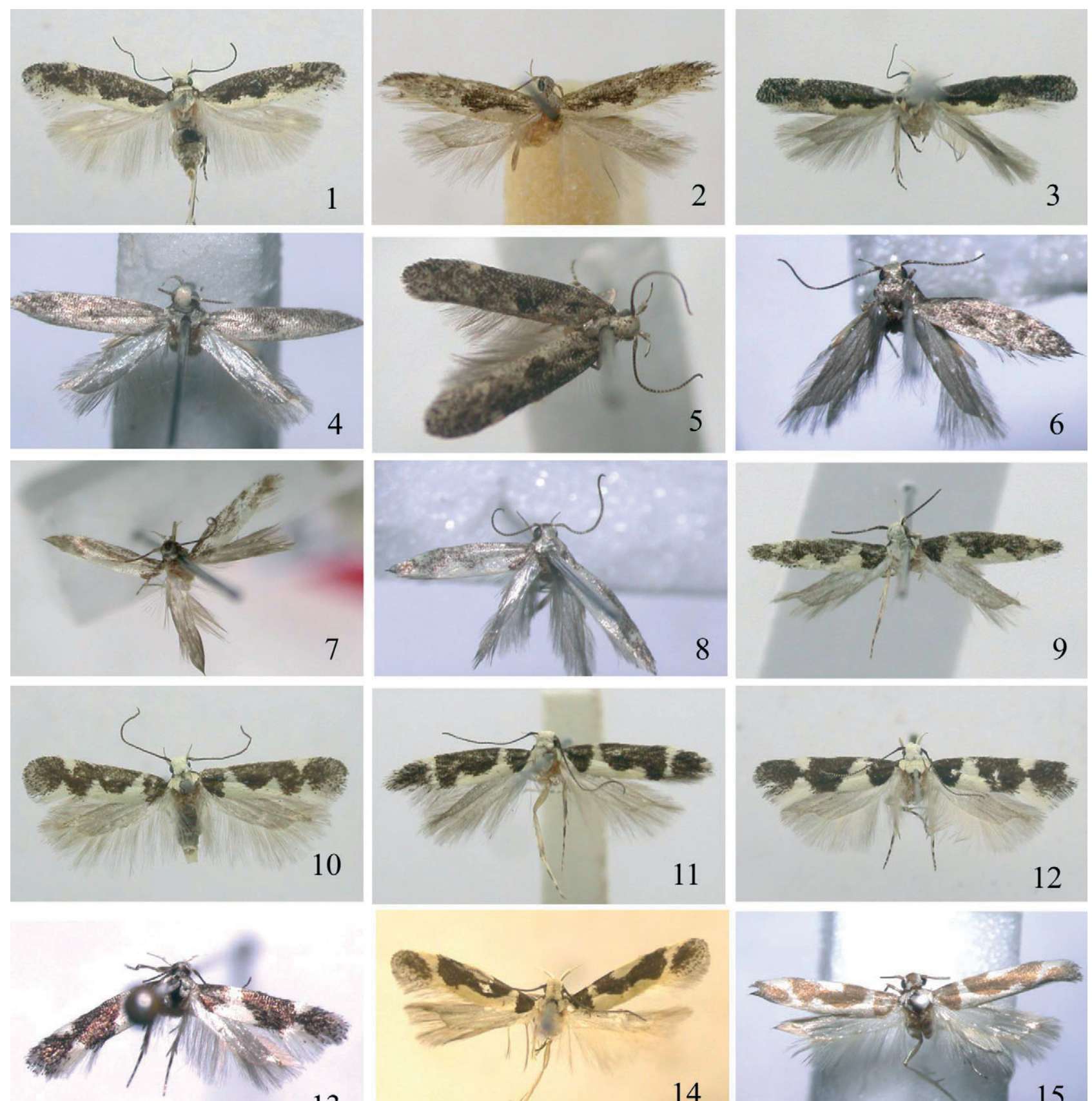

13
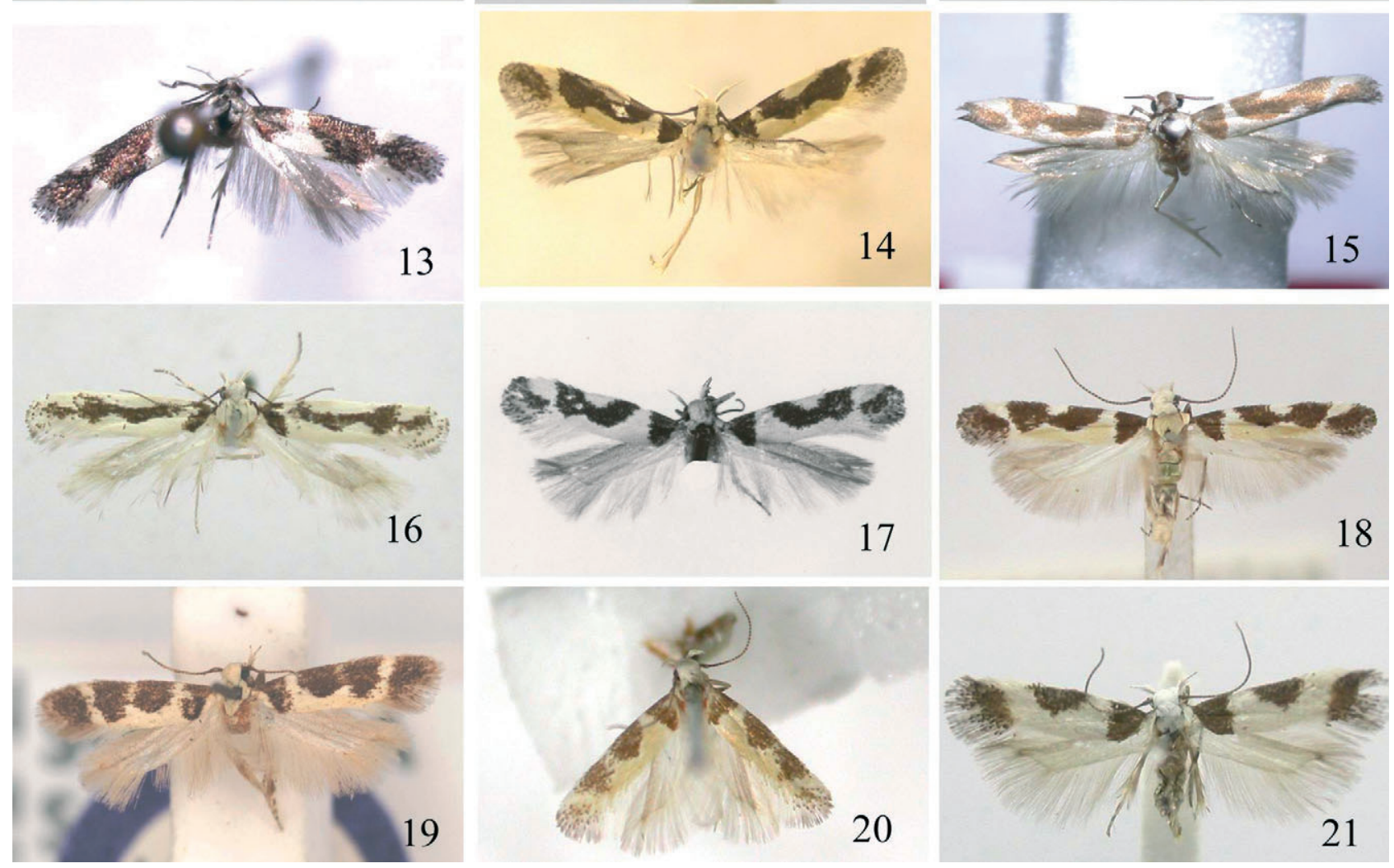
spots three-quarters along length; apex black-grey; cilia black. Hindwing light grey.

Male genitalia (Figs 22, 23, 46, 47). Sternite VIII constricted medially, apex broad, rounded. Uncus apically rounded. Ventral part of gnathos gradually widens distally, apex with three relatively narrow processes. Cucullus digitate, weakly curved or straight, not exceeding top of uncus, apex broadly rounded with distinct tooth. Sacculus short, nearly rounded. Saccus parallel-sided, apically rounded. Juxta lobes short, rounded. Vesica with distinct long needle-shaped cornuti.

Female genitalia (Fig. 69). Segment VIII trapezoid, slightly broader than long. Apophyses anteriores straight, nearly as long as length of segment VIII. Antrum tubular or funnel-shaped, shorter than apophyses anteriores. Corpus bursae large, rounded; accessory bursae with long row of small teeth. Signum cap-shaped with irregular medial transverse ridge, apical part rounded, anterior margin weakly emarginated. Variation: Antrum varies in shape and length from tubular, slightly shorter than apophyses anteriores to funnel-shaped, nearly half the length of the apophyses anteriores.

Biology. Host-plant unknown. Adults fly from June to July.

Distribution. South-East Europe: Macedonia, Greece; Turkey, Syria.

Remarks. Agnippe penicillata is described from a single male from the Taurus Mts, Syria. In its external appearance and structure of the male genitalia (Figs 2, 23) it is similar to $A$. lunaki.

\section{Agnippe syrictis (Meyrick, 1936)}

Recurvaria syrictis Meyrick, 1936. Lectotype đิ, Japan, labelled “Tokyo, Japan SI. 8.35" (slide No. 8246) (BMNH) [not examined].

Evippe syrictis (Meyrick, 1936): Okada, 1961; Clarke, 1969. Agnippe syrictis (Meyrick, 1936): Lee \& Brown, 2008.

Material. 1 $\delta^{\star}$, Russia, Novosibirsk Region, Ust'-Tarkskiy Dist., vill. Elanka, 5.viii.1998, P.J. Ustjuzhanin leg. (gen. prep. 52/07) (ZMKU); 1 ex, Kazakhstan, Semipalatinsk, 12.v.1928, Mal'kovskiy leg., ex larva; larva on Larix sibirica, 8.viii.1937 (ZIN); 1 ㅇ, Mongolia, Bajan-Ulegeiskiy aimak, Ih-Dzhargalantyn-Gol River, 20 km NW Bulgana, 4.-6.viii.1980, Kerzhner leg. (gen. prep. 2/08) (ZIN); 1 , China, Panshan, Ji County, Tianjin City, 170 m, 21.vii.2004, Houhun Li leg. (gen. prep. 167/07) (NKUM); 10, China, Baligou, Yuhui County, Henan Province, $780 \mathrm{~m}$, 13.vii.2002, Xinpu Wang leg. (gen. prep. 201/07) (NKUM); 10, China, Forest Farm, Qiuqianjia, Mt. Liupan, Ningxia Huizu Autonomus Region, 1.vii.2008, 1,700 m, Shulian Hao \& Zhiwei Zhang leg. (NKUM).
Diagnosis. This species is characterized externally by the dark-grey costal and whitish posterior margin on the forewing, very similar to that in A. lunaki. The male genitalia differ from those of $A$. lunaki in the apically broadened, sub-triangular and distinctly medially constricted cucullus. This species differs from $A$. lunaki and other species of Agnippe in the gnathos having a relatively narrow apex with thin processes located close to one another. The female genitalia differ slightly from those of A. lunaki in the shape of signum, which is broadly rounded anteriorly with a sub-rectangular apical part in $A$. syrictis, but weakly emarginated anteriorly and with a rounded apical part in $A$. lunaki. Differences from $A$. novisyrictis see below.

Adult (Fig. 3). Wingspan 8.0-9.0 mm. Head and thorax yellow-white. Labial palpus with outer surface of segment 2 black, apical one-third white, inner surface white; segment 3 white with black apex. Scapus black, other antennal segments white, ringed with black basally. Tegula black. Costal part of forewing black, posterior part yellow-cream, costal margin with small yellow-white spots located three-quarters along length; apex black-grey; cilia black. Hindwing light grey.

Male genitalia (Figs 24, 48). Sternite VIII basally broad, distal portion very narrow, apex rounded. Uncus apically rounded. Ventral part of gnathos gradually widens distally, apex relatively narrow, with three very narrow processes located close to one another. Cucullus with a distinct constriction two-thirds along its length, straight, not exceeding top of uncus; apex broad, subtriangular with distinct tooth. Sacculus short, nearly rounded. Juxta lobes short, slightly elongate, rounded apically. Saccus parallel-sided, apically rounded or weakly pointed. Vesica with a plate and long needle-shaped cornuti.

Female genitalia (Fig. 70). Segment VIII trapezoid, distinctly broader than long. Apophyses anteriores straight, nearly as long as length of segment VIII. Antrum tubular, shorter than apophyses anteriores. Corpus bursae rounded; accessory bursae with long row of small teeth. Signum cap-shaped, with irregular medial transverse ridge, apical part sub-rectangular, anterior margin broadly rounded.

Biology. Life history and larvae are described by $\mathrm{M}$. Okada (1961: 45-46). Larvae feed on Pinus spp. (Pinaceae) in Japan. Adults fly in July-August, probably two or three generations. One specimen without abdomen from Kazakhstan, which is similar externally to $A$. syrictis, was found in the collection of ZIN. According to data on the label the larvae damage Larix sibirica in

Figs 1-21. Adults of Agnippe species. 1 - A. lunaki, Macedonia; 2 - A. lunaki (=A. penicillata, holotype), Syria (gen. prep. 458; 468c, K. Sattler); 3 - A. syrictis, China (gen. prep. 167/07); 4 - A. novisyrictis, holotype, China (gen. prep. 89316); 5 -A. novisyrictis, China; 6 - A. yongdengensis, holotype, China (gen. prep. 89361); 7 -A. dichotoma, holotype, China (gen. prep. L92014); 8 - A. echinulata, holotype, China (gen. prep. L92033); 9 - A. echinulata, China (gen. prep. 206/07); 10 - A. echinuloides sp. n., paratype, Russia: Guberli; 11 - A. turanica sp. n., holotype, Uzbekistan (gen. prep. 43/07); 12 - A. albidorsella, Korea (gen. prep. 122/07); 13 - A. zhouzhiensis, paratype, China (gen. prep. L92051); 14 - A. kuznetzovi, holotype, Mongolia; 15 - A. kuznetzovi (=A. zhengi, holotype), China (gen. prep. L93071); 16 - A. deserta sp. n., holotype, Uzbekistan (gen. prep. 51/07); 17 - A. conjugella, lectotype, Alai; $18-A$. conjugella (=A. haberlandi, holotype), Afghanistan; $19-A$. pseudolella, lectotype, Russia: Sarepta; $20-A$. miniscula, China; 21 - A. separatella sp. n., holotype, S Iran. 

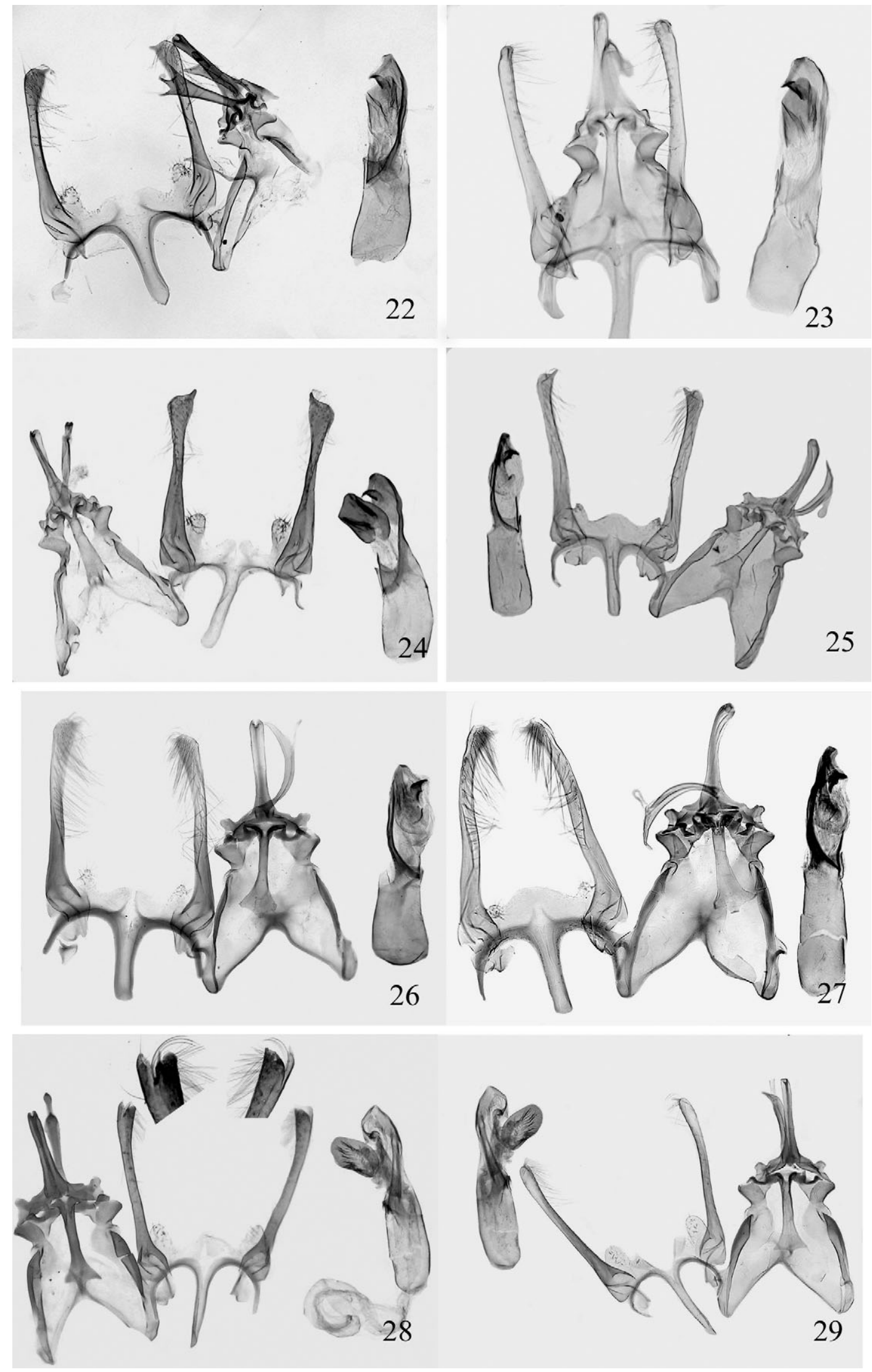

Figs 22-29. Male genitalia of Agnippe species. 22 - A. lunaki, Turkey (gen. prep. 164/07); 23 - A. lunaki (=A. penicillata, holotype), Syria (gen. prep. 458; 468c, K. Sattler); 24 - A. syrictis, China (gen. prep. L92056); 25 - A. novisyrictis, holotype, China (gen. prep. 89316); 26 - A. novisyrictis, Russia: Primorsky Region (gen. prep. 237/08); 27 - A. yongdengensis Li, holotype, China (gen. prep. 89361); 28 - A. dichotoma Li, holotype, China (gen. prep. L92014); 29 - A. echinulata Li, holotype, China (gen. prep. L92033). 
August and adults emerge in May the following year. The records from Prunus armeniaca and P. persica (Li, 2002: 135) require confirmation.

Distribution. Russia: Novosibirsk Region; East Kazakhstan; Mongolia; China: Ningxia, Henan, Tianjin; Korea; Japan.

\section{Agnippe novisyrictis (Li, 1993)}

Evippe novisyrictis Li, 1993. Holotype đo, China, labelled "3.vi.[19]85, Yangling, Shaanxi Province, 450 m, Li Houhun" (gen. prep. 89316) (NKUM) [examined].

Agnippe novisyrictis (Li, 1993): Lee \& Brown, 2008.

Type material. Holotype of novisyrictis as above; 10 paratype, same data as holotype, but 3.viii.1985, gen. prep. 89289 (NKUM); 10 paratype, China, "Forest Farm, Mt. Xinjia, Feng County, Shaanxi Province, 1600 m, 10.vii.1988, Houhun Li". (gen. prep. 89293) (NKUM)

Additional material. 1 $\delta$, China, Baligou, Yuhui County, Henan Province, 780 m, 13.vii.2002, Xinpu Wang leg. (gen. prep. 195/07) (NKUM); 10 , China, Suanzaoping, Neiqiu County, Hebei Province, 670 m, 28.vii.2000 (NKUM); 10 , 1 우 Russia, Russian Far East, Primorsky Region, Shkotovo Distr., Anisimovka, 21.viii.1994, N. Savenkov leg. (gen. prep. 237/08 đ; 537/07 ) (ZMUC)

Diagnosis. Externally may be confused with sympatrically distributed A. syrictis, but differs in dark, grey rather than white-cream posterior margin on forewing with a distinct brown medial spot, cream rather than white head and segment 2 of labial palpus that is mottled with brown. The male genitalia differ from that of $A$. syrictis in usually having a longer, medially broad, slightly curved inwards and round apically (rather than medially narrow and sub-triangular apically) cucullus, and distinctly shorter and narrower, weakly pointed, apically subtriangular (rather than broadly rounded) sacculus. Sternite VIII of $A$. novysirictis is slightly shorter, broader apically and not constricted medially as in A. syrictis. The female genitalia differ from those of $A$. syrictis, A. lunaki and most other species of Agnippe in having a longer antrum, which far exceeds the length of the apophyses anteriores. Both $A$. syrictis and $A$. novisyrictis may be found in the same biotopes. For differences from $A$. yongdengensis see under that species.

Adult (Figs 4-6). Wingspan 8.0-9.0 mm. Head, thorax and labial palpus light brown to cream. Segment 2 of labial palpus black from base to two-thirds on outer surface, rarely with mottled brown scales. Scapus brown, other antennal segments white, ringed with black basally. Tegula brown. Forewing grey-brown, posterior margin grey-cream, densely mottled brown; distinct brown spot on middle of wing; costal margin with cream spot threequarters along length; cilia grey, black-tipped. Hindwing light grey.

Male genitalia (Figs 25-27, 49-52). Sternite VIII constricted medially, apex broad, rounded. Uncus apically rounded, with relatively deep incision. Ventral part of gnathos gradually widens distally, apex relatively broad, lateral processes short, broadly separated. Cucullus relatively broad, inner margin slightly wider at one-third, apex rounded with distinct tooth, not exceeding top of uncus. Sacculus very short, triangular. Juxta lobes broad, rounded. Saccus parallel-sided, apex abruptly cut or weakly narrowed. Vesica with long needle-shaped cornuti.

Female genitalia (Fig. 71). Segment VIII elongate, nearly twice as long as broad. Apophyses anteriores shorter than segment VIII, weakly curved. Antrum tubular, distinctly longer than apophyses anteriores. Corpus bursae large, sub-oval; accessory bursae broad, with row of small teeth. Signum cap-shaped, with irregular medial transverse ridge, apical part rounded, finely serrated, anterior margin straight, irregularly serrated.

Biology. Host plant unknown. Adults fly in July-August.

Distribution. China: Gansu, Hebei, Henan, Shaanxi; Russia: Primorsky Region.

Remarks. See under A. yongdengensis.

\section{Agnippe yongdengensis $(\mathrm{Li}, 1993)$}

Evippe yongdengensis Li, 1993. Holotype đo, China, labelled "Yongdeng, Gansu Province, 6.vii.[19]85, Li Houhun" (gen. prep. 89361) (NKUM) [examined].

Agnippe yongdengensis (Li, 1993): Lee \& Brown, 2008.

Type material. Holotype of yongdengensis as above.

Diagnosis. Externally it is very similar to A. novisyrictis. The male genitalia are also extremely similar to those of $A$. novisyrictis, but differ slightly in that the sacculus is shorter and rounded rather than pointed, sternite VIII strongly constricted medially (Fig. 52) and tergite VIII with a nearly straight rather than strongly emarginated anterior margin (see Li, 1993, Figs 4c, 7c).

Adult (Fig. 6). Wingspan $10 \mathrm{~mm}$. Head, thorax and labial palpus light brown to cream. Outer surface of the basal two-thirds of segment 2 of labial palpus black, rarely with mottled brown scales. Scapus brown, other antennal segments white, ringed with black basally. Tegula brown. Forewing grey-brown, posterior margin grey-cream, densely mottled brown; distinct brown spot in middle of wing; costal margin with cream spot threequarters along its length; cilia grey, black-tipped. Hindwing light grey.

Male genitalia (Figs 27, 52). Sternite VIII constricted medially, apex broad, rounded. Uncus apically rounded, with relatively deep incision. Ventral part of gnathos gradually widens distally, apex relatively broad, lateral processes short, broadly separated. Cucullus relatively broad, inner margin slightly widened one-third along its length, apex rounded with distinct tooth, not exceeding top of uncus. Sacculus very short, rounded apically. Juxta lobes broad, rounded. Saccus parallel-sided, apex abruptly cut or weakly narrowed. Vesica with long needle-shaped cornuti.

Female unknown.

Biology. Host plant unknown. The holotype was collected in early July.

Distribution. China: Gansu.

Remarks. The description of Agnippe yongdengensis is based on a single male in very poor condition (Fig. 6), which externally resembles $A$. novisyrictis. The male 

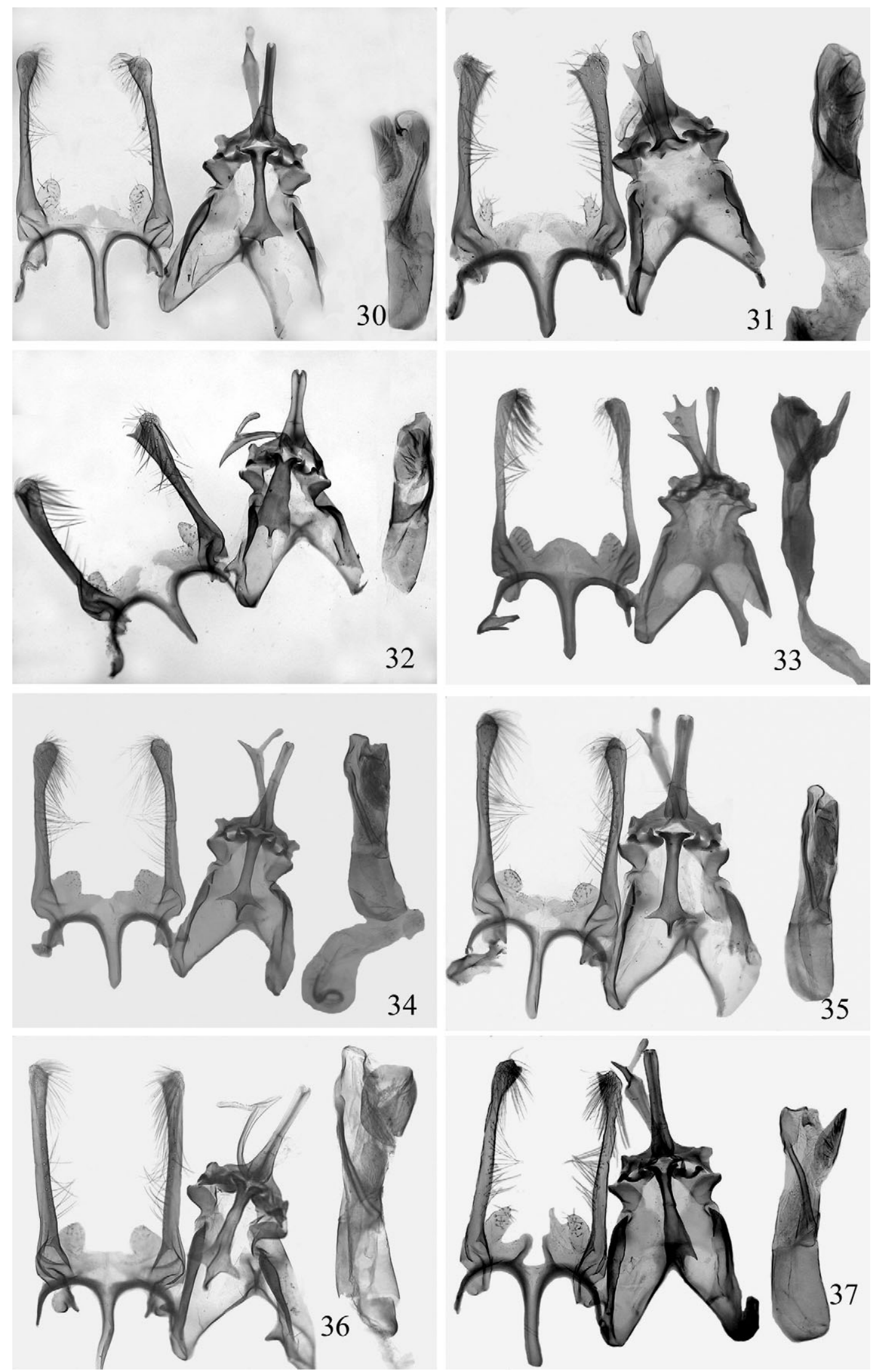

Figs 30-37. Male genitalia of Agnippe species. 30 - A. echinulata, China (gen. prep. 206/07); 31 - A. echinuloides sp. n., paratype, Russia: Guberli (gen. prep. 223/08); 32 - A. echinuloides sp. n., paratype, Russia: Transbaikalia (gen. prep. 49/07); $33-A$. turanica sp. n., paratype, Kazakhstan (gen. prep. 32/09); 34 - A. albidorsella, Korea (gen. prep. 239/08); 35 - A. albidorsella, Transbaikalia (gen. prep. L93071); 36 - A. zhouzhiensis, holotype, China (gen. prep. L92051); 37 - A. kuznetzovi, Mongolia (gen. prep. 173/07). 
genitalia are very similar to those of $A$. novisyrictis, but differ slightly in small details (see under Diagnosis). Further specimens including females need to be studied to clarify the taxonomic status of this species.

\section{Agnippe echinulata (Li, 1993)}

Evippe echinulata Li, 1993. Holotype đ, China, labelled "Chengcheng, Shaanxi Province, 30.vii.1986, Li Houhun" (gen. prep. L92033) (NKUM) [examined].

Agnippe echinulata (Li, 1993): Lee \& Brown, 2008.

Type material. Holotype echinulata as above; 10 paratype, same data as holotype.

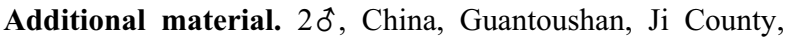
Shanxi Province, 15.viii.2002, Yanli Du leg. (gen. prep. 206/07ठ) (NKUM).

Diagnosis. Externally resembles A. conjugella, but differs in fused sub-costal black spots. The male genitalia are characterized by very slender, straight, distally bulbous valva and an aedeagus with a distinct plate of minute spines in vesica. For differences from $A$. echinuloides $\mathrm{sp}$. $\mathrm{n}$. see below.

Adult (Figs 8, 9). Wingspan 8.0-9.0 mm. Head, thorax, tegula and labial palpus white. Outer surface of base of segment 2 of labial palpus black. Scapus black, other antennal segments white, ringed with black basally. Forewing with black basal patch and two black subtriangular spots fused near costal margin; posterior half of forewing white; apex black, usually separated by narrow white fascia, but sometimes connected with sub-costal spots; cilia light grey, black-tipped. Hindwing light grey.

Male genitalia (Figs 29, 30, 54). Sternite VIII weakly constricted medially, basal portion about as long as length of distal portion. Uncus relatively narrow, apically rounded with small incision. Ventral part of gnathos gradually widens distally, apex relatively broad, lateral processes very short, broadly separated. Cucullus slender, nearly straight, apex distinctly or moderately rounded with distinct tooth, not exceeding top of uncus. Sacculus weakly elongate, rounded apically. Juxta lobes short, rounded. Saccus parallel-sided or weakly narrowed distally, apex abruptly cut or pointed. Vesica with a plate and long needle-shaped cornuti.

Female unknown.

Biology. Host plant unknown. Adults fly from the end of June to August.

Distribution. China: Shaanxi, Shanxi.

Remarks. See under $A$. dichotoma.

\section{Agnippe dichotoma (Li, 1993)}

Evippe dichotoma Li, 1993. Holotype ô, China, labelled "Chengcheng, Shaanxi Province, 29.vii.1986, Li Houhun" (gen. prep. L92014) (NKUM) [examined].

Agnippe dichotoma (Li, 1993): Lee \& Brown, 2008.

Type material. Holotype dichotoma as above.

Diagnosis. This species is very similar to $A$. echinulata externally and in the male genitalia, but differs slightly in having an apically bifurcated cucullus and longer lateral processes on the gnathos.
Adult (Fig. 7). The holotype is in very poor condition, but is similar externally to A. echinulata.

Male genitalia (Figs 28, 53). Sternite VIII weakly constricted medially, distal portion narrow. Uncus relatively narrow, apically rounded with small incision. Ventral part of gnathos gradually widens distally, apex relatively broad, lateral processes moderately short, pointed, broadly separated. Cucullus slender, nearly straight, apex rounded, divided medially in two short lobes, not exceeding top of uncus. Sacculus weakly elongate, rounded apically. Juxta lobes short, rounded. Saccus nearly parallel-sided, slightly narrower distally. Vesica with a plate and long needle-shaped cornuti.

Female unknown.

Biology. Host plant unknown. The holotype was collected at the end of June.

Distribution. China: Shaanxi.

Remarks. Agnippe dichotoma was described from a single male, which is similar externally to A. echinulata. The male genitalia are also very similar to those of $A$. echinulata, but differ slightly in having distally bifurcated valvae and longer lateral processes on gnathos. Further material including females needs to be studied to clarify the taxonomic status of this species.

\section{Agnippe echinuloides sp. n.}

Type material. Holotype $\subsetneq$, Russia, labelled "S Tuva, oz. [lake] Tere-Khol', 18.-19.vi.2001, 1250 m, p. pustynja [semidesert], P. Ustjuzhanin" (gen. prep. 48/07) (ZMKU); Paratypes: $10^{\star}$, same data as holotype; $30^{\star}$, Russia, labelled "Guberli", "27 15 6", "92", "Chr", "Pseudolella", "Col. b. Vel. Kn. Nikolaja Mikhailovicha" (gen. prep. 223/08) (ZIN); $1 \delta^{\star}$, Russia, labelled "poima [Valley] Tes-Khem river near Erzin [vill.], Tuva, 24.vi.1969, Yu. Kostjuk"; 10, Russia, labelled “Tuva, Erzinskiy r-n [Distr.], poima r. [Valley of River] Tes-Khem, mokhovoe boloto [moss bog], 8.vi.1968, Yu. Kostjuk" (gen. prep. 50/07) (ZMKU); 10ิ, Russia, labelled "Daurskie stepi [Dahurian steppes], okr. Ust'-Borzi [environs of Ust'-Borzya], na svet [at light], 24.vi.1989, I. Kostjuk" (gen. prep. 49/07) (ZMKU); 1 б, labelled "Mongolia, Mongolskiy Altai, $100 \mathrm{~km}$ SE p. [Pass] Darvi, chr. [Mt. Range] Darviin-Nuuru, H=1700 m, 20.vi.1999, leg. Ustjuzhanin P. Ja.” (gen. prep. 224/08) (ZMKU).

Diagnosis. Externally similar to A. echinulata, but differs in the broader cucullus with medially (rather than apically) placed cornutus, broader uncus and gnathos, and shorter, sub-triangular saccus. Both species also differ in male abdominal sternite VIII, which is narrow and elongate in A. echinulata and broad and short in A. echinuloides sp. n. The female genitalia resemble those of $A$. syrictis by having short antrum, but differ in the shape of signum.

Adult (Fig. 10). Wingspan 10.0-11.0 mm. Head, thorax, tegula and labial palpus white. Outer surface of base of segment 2 of labial palpus black. Scapus black, other antennal segments white, ringed with black basally. Forewing with black basal patch and two black subtriangular spots fused near costal margin; posterior half of forewing white; apex black, usually separated by narrow white fascia, but sometimes connected by sub-costal spots; cilia light grey, black-tipped. Hindwing light grey. 

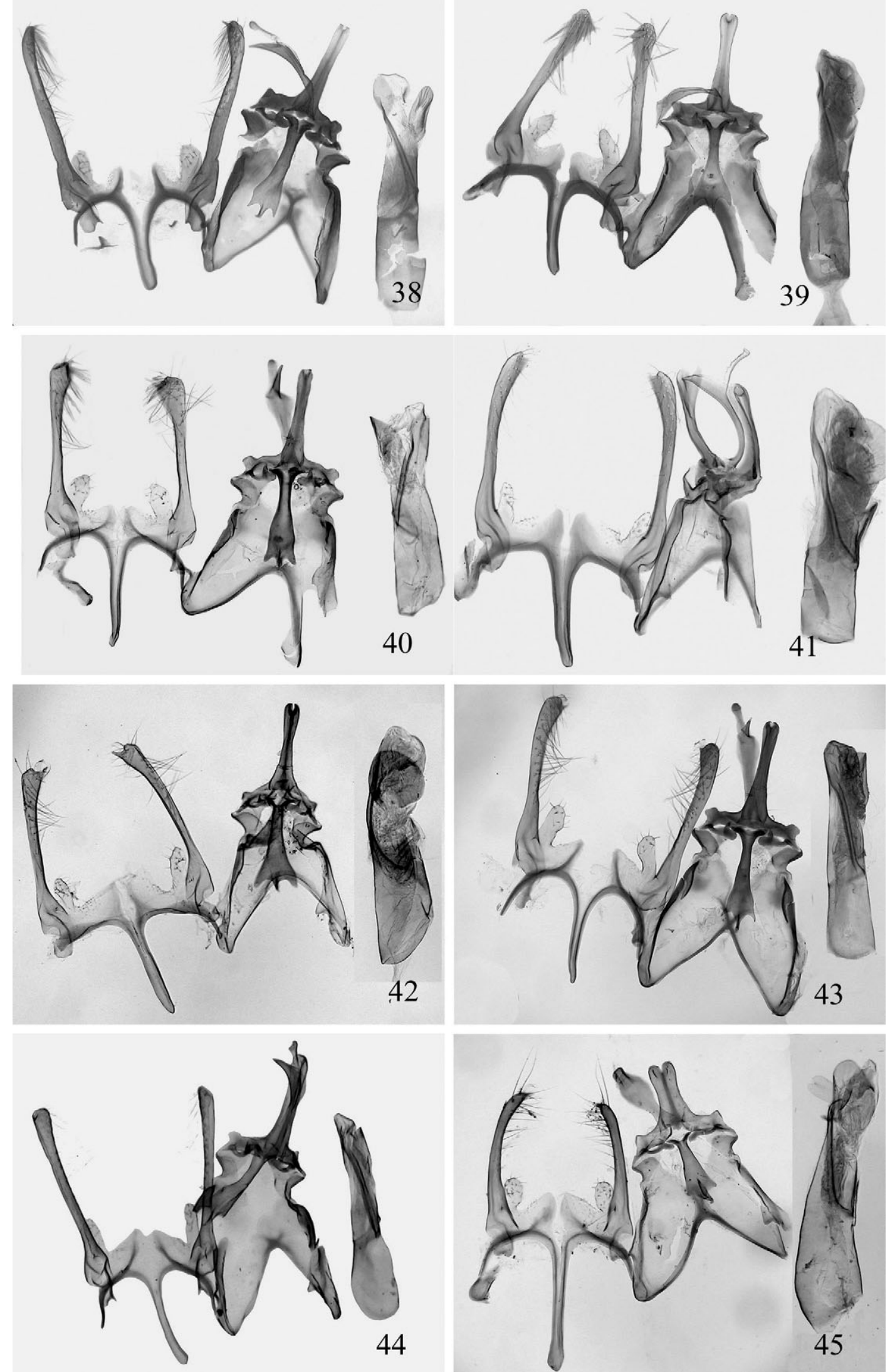

Figs 38-45. Male genitalia of Agnippe species. 38 - A. kuznetzovi (=A. zhengi, holotype), China (gen. prep. L93071); $39-A$. deserta sp. n., paratype, Uzbekistan (gen. prep. 248/07); 40 - A. conjugella, Uzbekistan (gen. prep. 163/07); 41 - A. pseudolella, Turkey (gen. prep. 199/08); 42 - A. pseudolella, Russia: Baskunchak (gen. prep. 168/07); 43 - A. pseudolella, China (gen. prep. 200/07); 44 - A. miniscula, China (gen. prep. L92034); 45 - A. separatella sp. n., paratype, Iran (gen. prep. 157/07). 
Male genitalia (Figs 31, 32, 55, 56). Sternite VIII broad, distal portion short, slightly narrower than basal portion. Uncus relatively wide, apically rounded with distinct incision. Ventral part of gnathos broad, gradually widened distally, apex broad, lateral processes short, broadly separated. Cucullus straight, apex rounded with long tooth, slightly exceeding top of uncus. Sacculus slender, digitate, weakly pointed distally. Juxta lobes short, slightly elongate. Saccus short, weakly narrowed apically. Vesica a plate, with long needle-shaped cornuti.

Female genitalia (Fig. 72). Segment VIII trapezoid, nearly as long as broad. Apophyses anteriores slightly longer than segment VIII, weakly curved. Antrum tubular, abruptly cut, shorter than apophyses anteriores. Corpus bursae large, sub-oval; accessory bursae broad, with row of small teeth. Signum cap-shaped, with irregularly shaped medial transverse ridge, apical part rounded, weakly serrated, anterior margin broadly rounded, irregularly dentate.

Biology. Host plant unknown. Adults fly in June up to $1,700 \mathrm{~m}$ in mountains.

Distribution. Russia: South Ural, Tuva, Chita Region; Mongolia.

Etymology. The specific name reflects close relation of new species to A. echinulata.

\section{Agnippe turanica sp. $\mathrm{n}$.}

Evippe sp. 2: Falkovitsh \& Bidzilya, 2009.

Type material. Holotype + , Uzbekistan, labelled "Ajakguzhumdy, 40 km O Dzhing.[ildy], Kyzylkum, 8.vi.1969, Falkovitsh" (gen. prep. 43/07) (ZIN). Paratype 10ิ, Uzbekistan, labelled "Buchara, 9.vii.1928, A. Gerasimov" (gen.prep. 33/09) (ZIN); $1 \delta^{\hat{0}}, 4$ ㅇ, Uzbekistan, "Buchara, Yargah pr. Chatyrtshy,

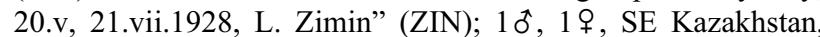
"150 km NE Alma-Ata, pravoi bereg r. Ili [right bank of Ili River], urochishche Myn-Bulak, 21.v.1990, Falkovitsh" (gen. prep. 32/09 $)$ (ZIN); 4ठ, 4우, "Kazakhstan, Petrovsk [=KzylOrda], na svet [at light]" (ZIN).

Diagnosis. This species resembles $A$. echinulata and $A$. echinuloides sp. n. superficially, but differs in the complete, not interrupted subapical fascia and rounded rather than triangular white pattern on the posterior margin of forewing. The male genitalia differ from those of externally similar species in broader sacculus and slightly longer cucullus. The female genitalia are characterized by the long, funnel-shaped gradually narrowing proximally antrum similar to that in $A$. kuznetzovi, but differ in the shape of signum and the shorter apophyses anteriores.

Adult (Fig. 11). Wingspan 9.5-10.5 mm. Head, thorax, tegula and labial palpus white. Outer surface at base of segment 2 of labial palpus black. Scapus black, other antennal segments white, ringed with black basally. Forewing with black basal patch and broad black medial pattern; posterior half of forewing white; apex black, separated by narrow white fascia; cilia light grey, blacktipped. Hindwing light grey.

Male genitalia (Figs 33, 57). Sternite VIII constricted medially, distal portion with broadly rounded apex. Uncus moderately wide, apically rounded with small incision. Ventral part of gnathos gradually widens distally, apex broad, lateral processes short, broadly separated. Cucullus slender, nearly straight, apex rounded with short teeth, extending to top of uncus. Sacculus relatively broad, sub-triangular. Juxta lobes short, slightly elongate. Saccus of equal width, rounded apically. Vesica with a plate and long needle-shaped cornuti.

Female genitalia (Figs 73, 74). Segment VIII trapezoid, nearly as long as broad. Apophyses anteriores slightly longer than segment VIII, straight. Antrum funnel-shaped, abruptly cut, about same length as apophyses anteriores. Corpus bursae rounded; accessory bursae short and broad, with row of small teeth. Signum cap-shaped, posterior portion with finely serrated margins, anterior margin irregularly dentate.

Biology. Host plant unknown. Adults fly in late May and early June.

Distribution. Uzbekistan, SE Kazakhstan.

Etymology. The specific name refers to the species distribution in the Turanian region.

\section{Agnippe albidorsella (Snellen, 1884)}

Recurvaria albidorsella Snellen, 1884. Holotype ô, Russia, labelled "Amoer" (RMNH) [not examined].

Evippe albidorsella (Snellen, 1884): Okada, 1961.

Agnippe albidorsella (Snellen, 1884): Lee \& Brown, 2008.

Material. $1 \delta^{\hat{\sigma}}$, Russia, Transbaikalia, environs of vill. Nizhnii Tsasuchei, pine forest, at light, 1.vii.1997, A. Bidzilya, I. Kostjuk, O. Kostjuk leg. (gen. prep. 171/07) (ZMKU); 1 đ, Russia, Transbaikalia, Chita Region, environs of vill. Kyra, 900 m, at light, 16.vii.1997, A. Bidzilya, I. Kostjuk, O. Kostjuk leg. (gen. prep. 233/08) (ZMKU); 10, Russia, Primorsky Region, Lazovskiy Nat. Res., vill. Glazkovka, at light, 13.viii.1992, A. Bidzilya leg. (gen. prep. 232/08) (ZMKU); 1 은 South Korea, Kangwon Nat. Univ., Chuncheon GW, 15.v.1997, Y.M. Park leg. (gen. prep. 172/07) (ZMKU); 10 , South Korea, Giamri GW, Chuncheon, 24.vii.1995, H.K. Lee leg. (gen. prep. 239/08) (ZMKU); $1 \hat{\delta}$, China, Mt. Baiyun, Yuxian, Henan Province, 1,580 m, 18.vii.2002, Xinpu Wang leg.; 2ð, China, Forest Farm, Tianshuidangchuan, Gansu, Province 1,331 m, 29.vii.2006, Xinpu Wang \& Xiangfeng Shi leg.; 1 , China, Wuyanling, Taishun, Zhejiang Province, 930 m, 31.vii.2005, Yunli Xiao leg.; 4ô, China, Forest Farm., Qiuqianjia, M. Liupan, Ningxia Huizu Autonomus Region, 2.vii.2008, 1,700 m, Shulian Hao \& Zhiwei Zhang leg.; $1 \hat{\widehat{s}}$, China, Forest Farm., Qiuqianjia, M. Liupan, Ningxia Huizu Autonomus Region, 07.vii.2008, 2,050 m, Shulian Hao \& Zhiwei Zhang leg. (NKUM).

Diagnosis. This species is characterized externally by the relatively large-sized and unique wing pattern, namely very broad black medial fascia. The male genitalia are characterized by a short rounded sacculus and relatively broad cucullus without or with very small apical horn. See also Remarks under A. zhouzhiensis.

Adult (Fig. 12). Wingspan 9.0-10.2 mm. Head, thorax, tegula and labial palpus white. Outer surface at base of segment 2 of labial palpus black. Scapus black, other antennal segments black with narrow white basal rings. Forewing with black basal and large black medial patches from costa to posterior margin, apex black; white triangular basal and white interrupted subapical fasciae three- 

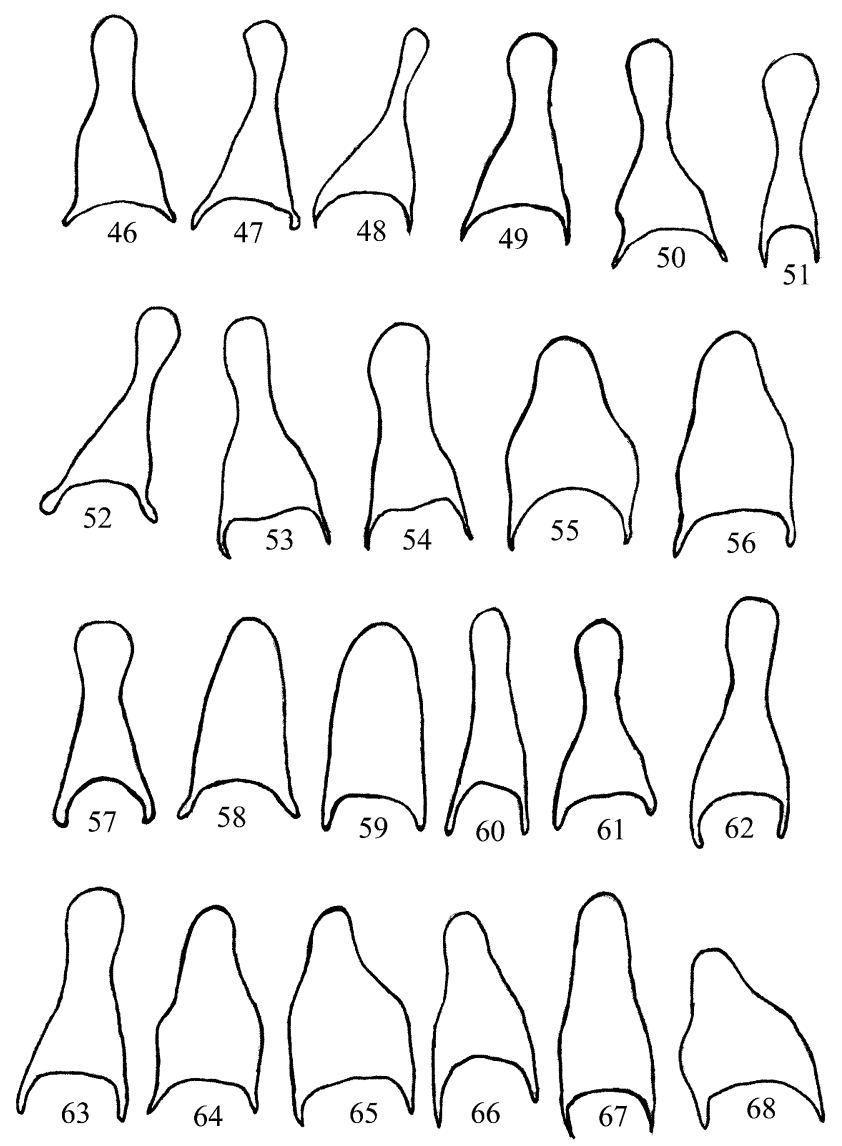

Figs 46-68. Male abdominal sternite VIII of Agnippe species. 46 - A. lunaki, Macedonia (gen. prep. 164/07); $47-A$. lunaki (=A. penicillata, holotype), Syria (gen. prep. $458,468 \mathrm{c}$, K. Sattler); 48 - A. syrictis, China (gen. prep. L92047); $49-A$. novisyrictis, holotype, China (gen. prep. 89316); $50-A$. novisyrictis, China (gen. prep. 89289); $51-$ A. novisyrictis, China, (gen. prep. 89293); 52 - A. yongdengensis, holotype, China; $53-A$. dichotoma, holotype, China; $54-A$. echinulata, holotype, China; $55-A$. echinuloides sp. n., Russia: Transbaikalia (gen. prep. 49/07); $56-A$. echinuloides sp. n., paratype, Russia: Guberli (gen. prep. 223/08); 57 - A. turanica sp. n., paratype, Kazakhstan (gen. prep. 32/09); $58-$ A. albidorsella, Korea (gen. prep. 239/08); 59 - A. albidorsella, Russia: Transbaikalia (gen. prep. 171/07); $60-$ A. zhouzhiensis, holotype, China; 61 - A. kuznetzovi, Mongolia (gen. prep. 173/07); $62-$ A. kuznetzovi (=A. zhengi, holotype), China (gen. prep. L93071); 63 - A. deserta sp. n., Uzbekistan (gen. prep. 213/08); 64 - A. conjugella, Uzbekistan (gen. prep. 163/07); $65-A$. pseudolella, Turkey (gen. prep. 199/08); $66-$ A. pseudolella, China (gen. prep. 200/07); 67 - A. miniscula, China (gen. prep. L92034); 68 - A. separatella sp. n., S Iran (gen. prep. 157/07).

quarters along length; cilia dark-grey, black-tipped. Hindwing light grey.

Male genitalia (Figs 34, 35, 58, 59). Sternite VIII weakly narrowed distally or nearly parallel-sided, weakly constricted medially. Uncus long and narrow, apically rounded with distinct incision. Ventral part of gnathos narrow, apex broad, lateral processes long and slender, broadly separated. Cucullus straight, widened distally, apex slightly pointed or rounded, without or with very small horn, not reaching top of uncus. Sacculus broad, rounded. Juxta lobes digitate. Saccus short, parallel-sided, apex rounded. Vesica with long needle-shaped cornuti.

Female genitalia (Fig. 75). Segment VIII trapezoid, nearly as long as broad. Apophyses anteriores about same length as segment VIII, straight. Antrum elongate, funnelshaped, gradually narrowed proximally, about same length as apophyses anteriores. Corpus bursae rounded; accessory bursae long and narrow, with row of small teeth. Signum sub-rhomboid, with irregularly dentate anterior margin.

Biology. Larvae feed on Lespedeza spp. (Fabaceae). Life history and larvae are described by M. Okada (1961: 44-45). Adults fly from May to August up to $1580 \mathrm{~m}$ in mountains. Okada (1.c.) mentions that this species has three or more generations a year in Japan.

Distribution. Russia: Primorsky Region, Amur Region, Chita Region; China: Gansu, Henan, Ningxia, Zhejiang; Korea; Japan.

\section{Agnippe zhouzhiensis (Li, 1993)}

Evippe zhouzhiensis Li, 1993. Holotype đ, China, labelled

"Zhouzhi, Shaanxi Province, 1000 m, 13.vii.1987, Li

Houhun" (gen. prep. L92051) (NKUM) [examined].

Agnippe zhouzhiensis (Li, 1993): Lee \& Brown, 2008.

Type material. Holotype of zhouzhiensis as above; paratype o with same data as holotype (gen. prep. L92050) (NKUM).

Additional material. $1 \%$, China, Shaliangzi, Zhouzhi County, Shaanxi Province, 1,000 m, 13.viii.1987, Houhun Li leg. (L92050) (NKUM); 1 \% , China, Yanglin, Shaanxi Province, 27.v.1985, Houhun Li leg. (89267) (NKUM); 1요 Russia, Ussuri [=Primorsky] Region, Suchan, source of Sitsa River, 5.viii.1928, Kurentzov leg. (ZIN).

Diagnosis. Externally and in the male genitalia this species is very similar to A. albidorsella. See also under Remarks.

Adult (Fig. 13). Wingspan 9.0-10.1 mm. Head, thorax, tegula and labial palpus white. Segment 2 of labial palpus black at base on outer surface. Scapus black, other antennal segments black with narrow white basal rings. Forewing with black basal and large black medial patches from costa to posterior margin, apex black; white triangular basal and white interrupted subapical fasciae threequarters along length; cilia dark-grey, black-tipped. Hindwing light grey.

Male genitalia (Figs 36, 60). Sternite VIII very narrow, weakly constricted medially. Uncus long and narrow, apically rounded with distinct incision. Ventral part of gnathos narrow, apex broad, lateral processes long and slender, broadly separated. Cucullus straight, widens distally, apex rounded with very small horn, not reaching top of uncus. Sacculus broad, rounded. Juxta lobes digitate. Saccus short, gradually narrowed distally. Vesica with long needle-shaped cornuti.

Female genitalia (Fig. 76). Segment VIII subrectangular, nearly as long as broad. Apophyses anteriores shorter than segment VIII, straight. Antrum short and broad, anterior margin weakly rounded, distinctly shorter than apophyses anteriores. Corpus bursae sub-oval; accessory bursae long and narrow, with row of small teeth. Signum sub-triangular with rounded corners, anterior margin irregularly dentate or broadly rounded. 


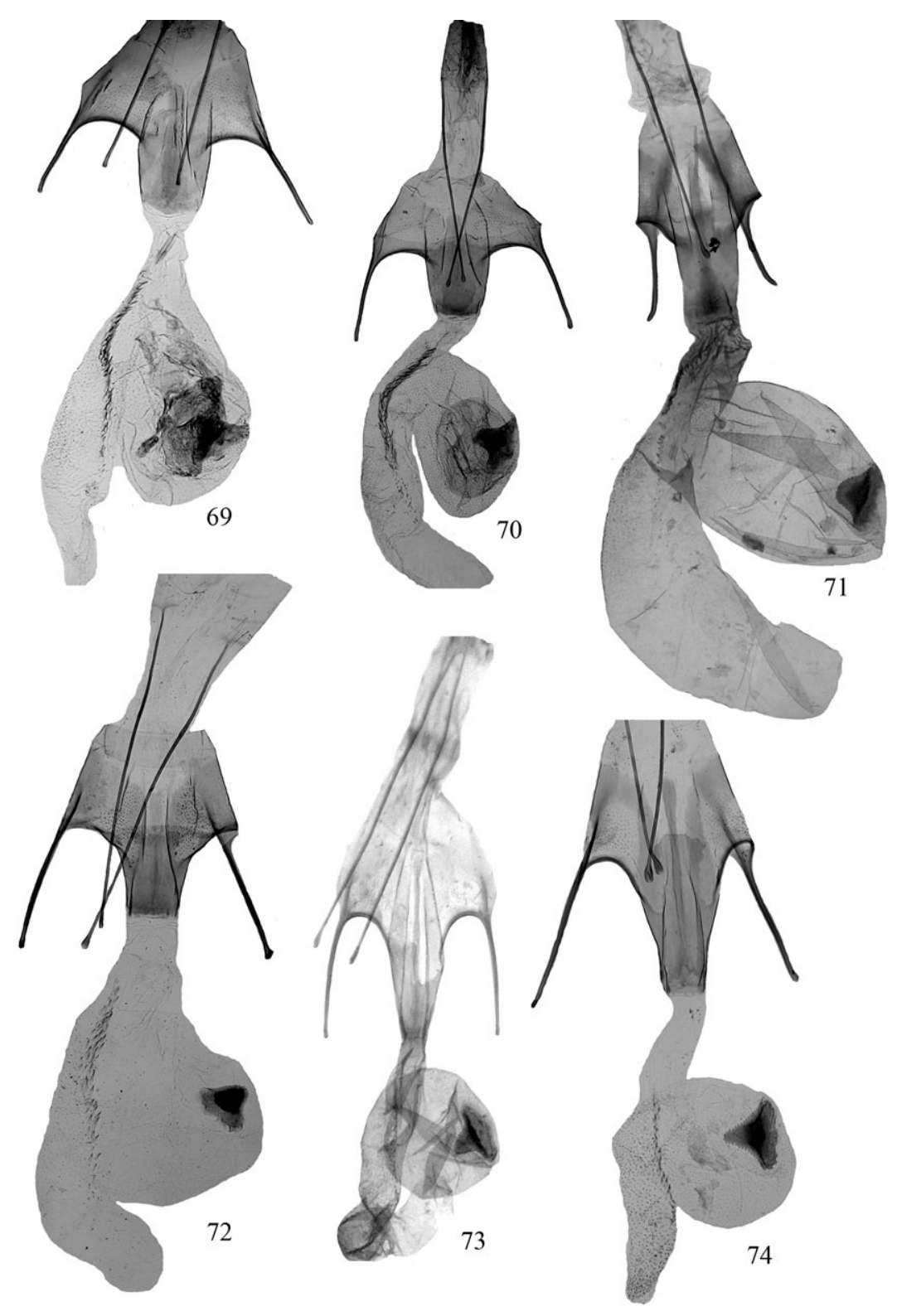

Figs 69-74. Female genitalia of Agnippe species. 69 - A. lunaki, Macedonia (gen. prep. 165/07); 70 - A. syrictis, China (gen. prep. 167/07); $71-$ A. novisyrictis, Russia: Primorsky Region (gen. prep. 537/07); 72 - A. echinuloides sp. n., holotype, Russia: Tuva (gen. prep. 48/07); 73 - A. turanica sp. n., paratype, Kazakhstan (gen. prep. 33/09); $74-$ A. turanica sp. n., holotype, Uzbekistan (gen. prep. 43/07).

Biology. Host plant unknown. Adults occur in July and August.

Distribution. China: Shaanxi; Russia: Primorsky Region. It can be supposed that $A$. zhouzhiensis is broadly distributed in Eastern Asia and some records of $A$. albidorsella refer to $A$. zhouzhiensis.

Remarks. Agnippe zhouzhiensis was described from two specimens of both sexes from Shaanxi Province. Externally and in the male genitalia it is very similar to $A$. albidorsella. The male genitalia of holotype of zhouzhiensis differ from those of $A$. albidorsella by the slightly longer, narrower saccus, and sternite VIII, which is very narrow and long in A. zhouzhiensis, but usually short and broad, sometimes tongue-shaped in A. albidorsella. The female genitalia of $A$. zhouzhiensis are characterized by a short and broad, anteriorly rounded antrum, whereas the antrum in $A$. albidorsella is distinctly elongate, funnelshaped; signum in A. zhouzhiensis is sub-triangular, but rhomboid in A. albidorsella. These two species are externally similar and closely related, but clearly differ in the structure of the female genitalia.

\section{Agnippe kuznetzovi (Lvovsky \& Piskunov, 1989)}

Evippe kuznetzovi Lvovsky \& Piskunov, 1989. Holotype đ, labelled "Mongolia, Bajan-Khongorskiy aimak, oasis EhinGol, dnem na sophore [daytime on Sophora], 10.vii.1981, Lvovsky" (ZIN) [examined].

Agnippe kuznetzovi (Lvovsky \& Piskunov, 1989): Lee \& Brown, 2008.

Evippe zhengi Wang \& Li, 1994, syn. n. Holotype đ, China, labelled "Zhongning County, Ningxia Huizu Autonomous 


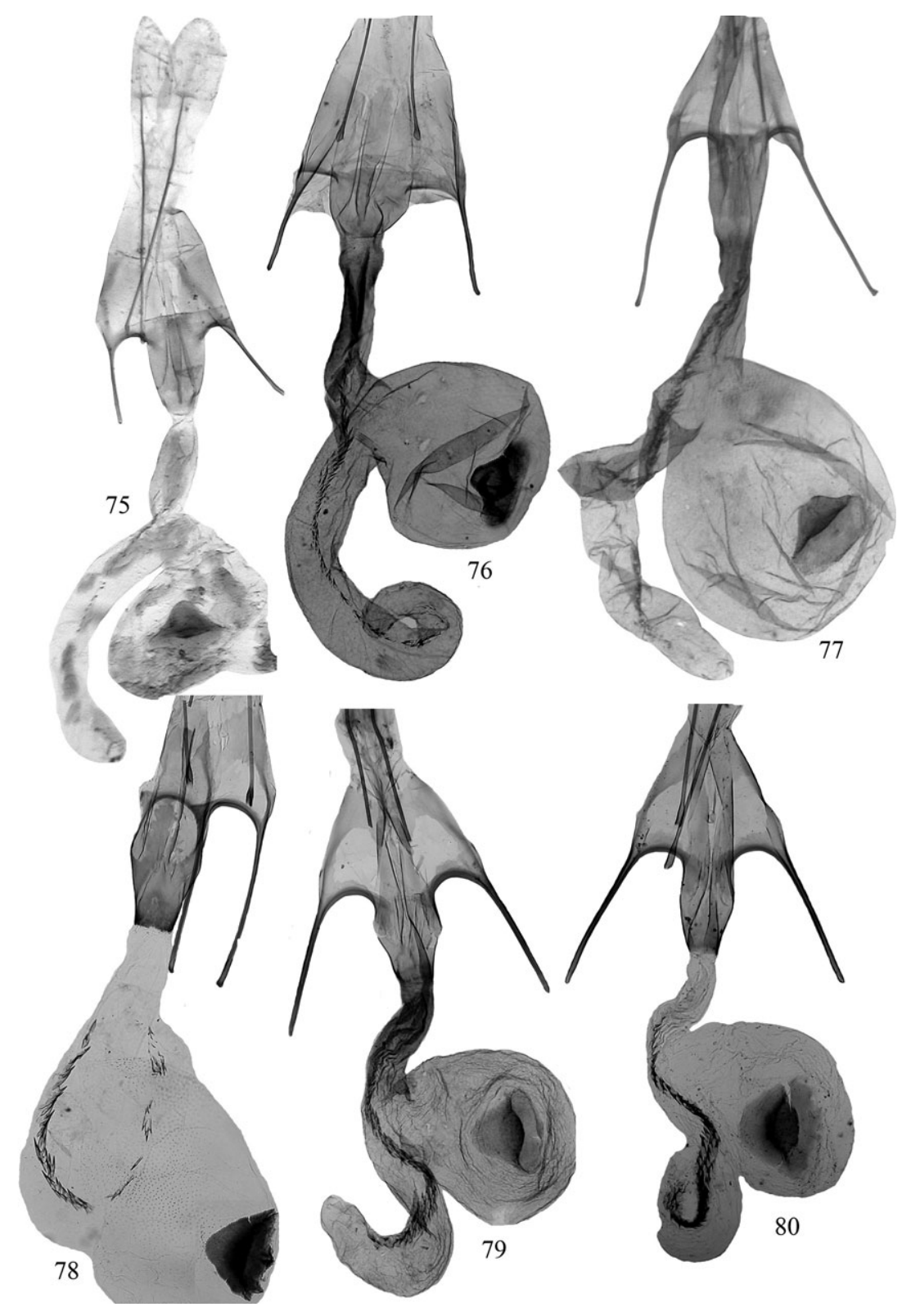

Figs 75-80. Female genitalia of Agnippe species. 75 - A. albidorsella, Korea (gen. prep. 172/07); 76 - A. zhouzhiensis, China (gen. prep. L07027); $77-A$. kuznetzovi, paratype, Mongolia (gen. prep. 30/09); $78-$ A. kuznetzovi (=A. zhengi), China (gen. prep. L96010); 79 - A. deserta sp. n., Uzbekistan, paratype (gen. prep. 247/08); 80 - A. deserta sp. n., Uzbekistan, paratype (gen. prep. 51/07).

Region, 1170 m, 16.vii.1993, coll. Houhun Li” (gen. prep. L93071) (NKUM) [examined].

Agnippe zhengi (Wang \& Li, 1994): Lee \& Brown, 2008.

Type material. Holotype of kuznetzovi as above, paratypes 110,26 으, same data as holotype (ZIN); holotype zhengi as above, paratype $\$$, same data as holotype (gen. prep. L93077) (NKUM).

Additional material. 10 , Mongolia, Ubsunur. aimak, UbsuNur, 50 km E Ulan-Goma, at light, 5.viii.1970, Kerzhner \& Chogsomzhav leg. (gen. prep. 173/07) (ZIN); 10, Kazakhstan, Sarytaukum, 150 km NNE Alma-Ata, 5.v.1981, Reznik leg. (gen. prep. 31/09) (ZIN); 10, China, Xiaoshang Village, M. Qipan, Weichang, Hebei Province, 17.vii..2001, Yanli Du \& Shulian Hao leg. (gen. prep. LZD01269) (NKUM).
Diagnosis. This species is easily recognized as the forewing has an elongate white medial costal spot. The male genitalia resemble those of $A$. conjugella, but differ in longer valva and slightly shorter saccus.

Adult (Figs 14, 15). Wingspan 8.5-10.0 mm. Head, thorax, tegula and labial palpus white. Segment 2 of labial palpus brown at base. Scapus black, other antennal segments black with narrow white basal rings. Forewing with black basal patch, with two overlapping black spots: medial spot at one-third and subapical spot at threequarters along costal margin; posterior half of forewing and elongate medial sub-costal spot white; apex with distinct black touch; cilia light grey, black-tipped. Hindwing light grey. 

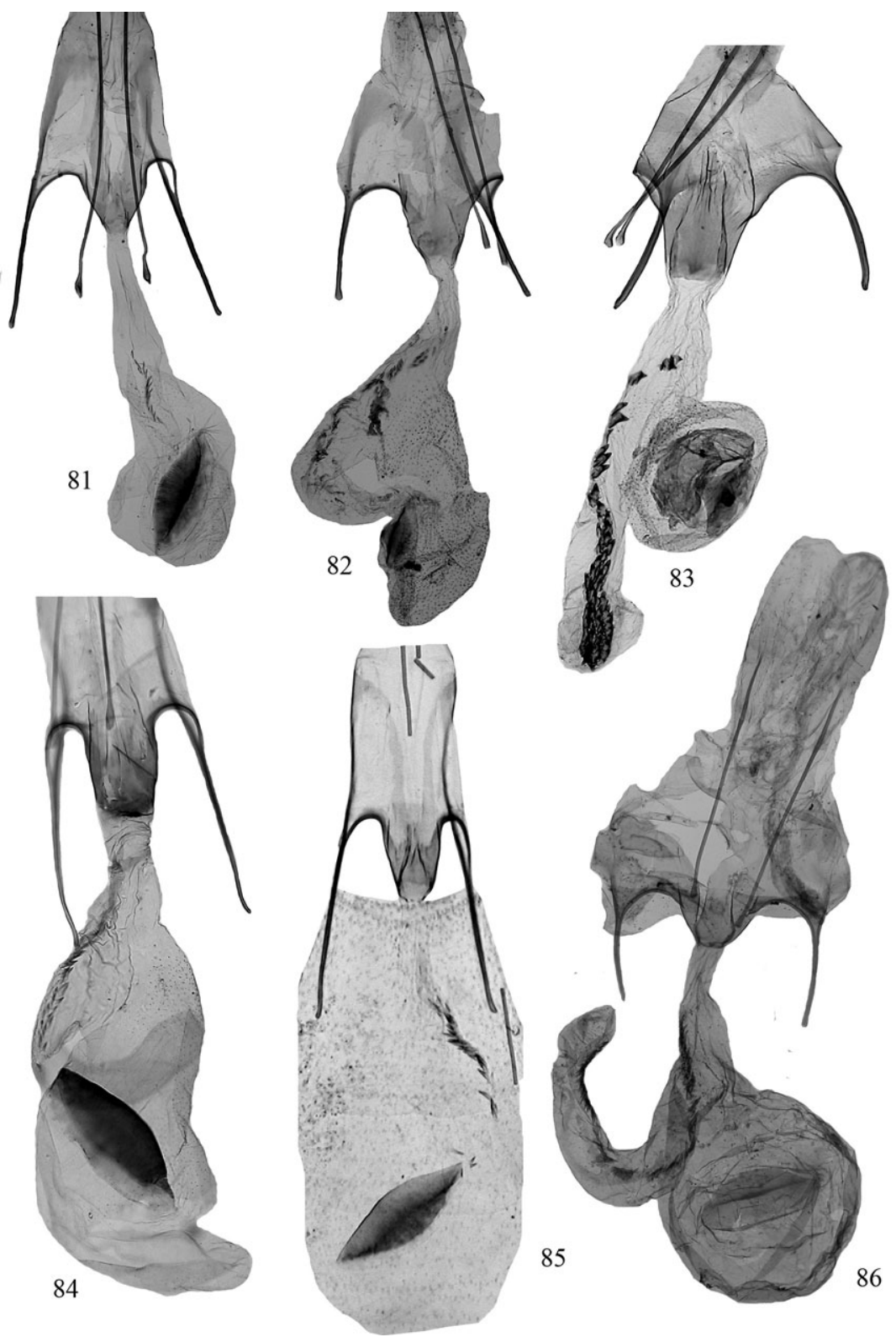

Figs 81-86. Female genitalia of Agnippe species. 81 - A. conjugella, N Iran (gen. prep. 176/07); 82 - A. conjugella, Uzbekistan (gen. prep. 163/07); 83 - A. pseudolella, Turkmenistan (gen. prep. 169/07); $84-A$. miniscula, China (gen. prep. L07045); $85-A$. miniscula, China (gen. prep. 89286); 86 - A. separatella sp. n., S Iran, paratype (gen. prep. 162/07).

Male genitalia (Figs 37, 38, 61, 62). Sternite VIII constricted medially, distal portion moderately narrow, apex rounded. Uncus long and narrow, apically rounded with small incision. Ventral part of gnathos gradually widens distally, apex relatively narrow, lateral processes triangular. Cucullus long and slender, straight, widens distally, apex rounded with small horn, distinctly not reaching top of uncus. Sacculus digitate. Juxta lobes elongate. Saccus nearly parallel-sided, apex rounded. Vesica with a few needle-shaped cornuti.

Female genitalia (Figs 77, 78). Segment VIII subrectangular, distinctly longer than broad. Apophyses anteriores longer than segment VIII, straight. Antrum long, funnel-shaped, with posterior two-thirds gradually narrowing, distinctly shorter than apophyses anteriores. Corpus bursae sub-oval; accessory bursae long and nar- row, with row of small teeth. Signum relatively large, with sub-trapezoid posterior and broadly rounded anterior portion.

Biology. Larvae feed on the spoon-shaped leaves of Pseudosophora alopecuroides L. (Fabaceae) (Lvovsky \& Piskunov, 1989: 564). Adults fly from July to early August.

Distribution. SE Kazakhstan; Mongolia: Bajan Khongorskiy aimak; China: Hebei, Ningxia.

Remarks. Agnippe zhengi was described from series of specimens of both sexes from Ningxia Huizu Autonomous Region. The genitalia of adults of both sexes of this taxon are similar to those of A. kuznetzovi, which is the reason for establishing the present synonymy. 


\section{Agnippe deserta sp. $\mathrm{n}$.}

Evippe sp. 1: Falkovitsh \& Bidzilya, 2009.

Type material. Holotype $\hat{\jmath}$, Uzbekistan, labelled "Kyzylkum, Zhamansai, $140 \mathrm{~km}$ NW Shafricana, 8.vi.1967, Falkovitsh" (ZIN). Paratypes: $10 \hat{\delta}, 1 \%$, same data (gen. prep.

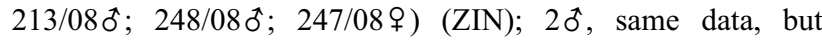
10.vi.[1]966 (ZIN); 10, Uzbekistan, "uroch.[ishche] Zhamansai, Kyzylkum, Uzbek.[istan], 26.v.[1]970, Falkovitsh" (gen. prep. 156/07) (ZIN); $2 \hat{0}$, same data, but 13.vi.[1]970 (ZIN); 1 \%, same data, but 2.vi.[1]975 (gen. prep. 51/07) (ZIN); 20 , same data, but 26.v.[1]970 (gen. prep. 40/07) (ZIN); 1 \%, Uzbekistan, "60 km SO Uchkuduka, pust. [desert] Kyzylkum, 7.v.[1]966, Pastukhov" (gen. prep. 180/07) (ZIN). 3 \% , Turkmenistan, "Turkmenia, Repetek, na svet [at light], 19.vii.1983; 4.viii.1983 (Krivokhatskiy)" (ZIN).

Diagnosis. This species resembles $A$. kuznetzovi externally, but differs in the longer white sub-costal spot, which is usually not interrupted by brownish fascia and is connected to the sub-apical white patch. The male genitalia are characterized by relatively short and broad genitalia capsula, remotely resembling those of $A$. echinuloides sp. n. The female genitalia may be recognized by the cap-shaped signum and medially broadened antrum, remotely similar to those in $A$. kuznetzovi.

Adult (Fig. 16). Wingspan 9.0-10.0 mm. Head, thorax, tegula and labial palpus white. Segment 2 of labial palpus brown at base. Scapus black, other antennal segments black with narrow white basal rings. Forewing with narrow, light brown basal patch, with two overlapping brown spots: medial spot one-quarter and sub-apical spot three-quarters along costal margin; posterior half of forewing and elongate medial sub-costal spot white; apex with distinct brown touch, which is often connected with sub-apical spot, forming longitudinal line from onequarter along costal margin to apex; cilia light grey, black-tipped. Hindwing light grey.

Male genitalia (Figs 39, 63). Sternite VIII weakly constricted medially, distal portion about as broad as basal portion. Uncus long and narrow, weakly broader distally, apex rounded with small incision. Ventral part of gnathos narrow, apex relatively narrow, lateral processes triangular. Cucullus slender, widens distally, apex rounded with distinct horn, distinctly not reaching top of uncus. Sacculus narrow, digitate. Juxta lobes short, narrow. Saccus nearly parallel-sided, apex rounded. Vesica with a few needle-shaped cornuti. Variation: One of the males examined (gen. prep. 213/08) had a slightly outwardly curving and less apically bulbous valva.

Female genitalia (Figs 79, 80). Segment VIII trapezoid, slightly longer than broad. Apophyses anteriores longer than segment VIII, straight. Antrum funnel-shaped, distinctly shorter than apophyses anteriores, slightly broader medially, narrower anteriorly. Corpus bursae rounded; accessory bursae long and narrow, with row of small teeth. Signum cap-shaped, anterior margin irregularly dentate. Variation: One female (gen. prep. 180/07) had a sub-triangular signum, but this specimen is similar externally to $A$. deserta.

Biology. Host plant unknown. Adults occur from early May to mid June.
Distribution. Uzbekistan, Turkmenistan.

Etymology. Specific name refers to the species being recorded from desert areas (Latin: deserta - desert).

\section{Agnippe conjugella (Caradja, 1920)}

Lita conjugella Caradja, 1920. Lectotype ô, Kyrgyzstan, "Alai" (slide no. Car. 2199, Povolný) (MGAB), designated by Popescu-Gorj (1992: 145) [not examined].

Stegasta conjugella (Caradja, 1920): Gaede, 1937.

Evippe conjugella (Caradja, 1920): Park, 1996.

Agnippe conjugella (Caradja, 1920): Lee \& Brown, 2008.

Evippe haberlandi Amsel, 1961, syn. n. Holotype o, "Afghanistan, Herat, 970 m, 5.v.1956, H.G. Amsel leg." (SMNK) [examined].

Agnippe haberlandi (Amsel, 1961): Lee \& Brown, 2008.

Type material. Holotype haberlandi as above, 7 paratypes, same data as holotype.

Additional material. 1 $\hat{\delta}$, Uzbekistan, Zhamansai, Kyzylkum, 2.iv.1979, Falkovitsh leg. (ZIN); 1 \%, same data but 2.ix.1969 (gen. prep. 163/07) (ZIN); 10, same data but 23.iv.1972 (ZIN); 1 $\widehat{\delta}$, Uzbekistan, environs of Dzharkurgan., Sukhandariya Region, 11.v.1966, sand, at light (gen. prep. 179/07) (ZIN); 1 \%, Turkmenistan, Ispas, 70 km NW Tchardzhou, 30.v.1965, Falkovitsh leg. (gen. prep. 178/07) (ZIN); 1 Turkmenistan, Repetek, SE Karakum, 23.v.1981, Falkovitsh leg. (ZIN); 20 3 9 , Turkmenistan, Repetek, 24.iv.1971, at light, Gur'eva leg. (ZIN). 1 9 , SE Kazakhstan, Alma-Ata Region, Uigurskiy Dist., Tcharyn River, "Jasenevaya roshcha", 24.vi.1990, M. Nesterov leg. (gen. prep. 246/08) (ZMKU); 1 \%, N Iran, Salzsee, 90 km S Teheran, 900 m, 21.vi.1975, H.G. Amsel leg. (gen. prep. 176/07) (SMNK); $2 \hat{0}$, Tajikistan, Gissar Ridge, Tigrovaya Balka, 28.iv.1966, A.S. Danilevsky leg. (ZIN); 1 ㅇ, E Afghanistan, Pol-i-Carchi, 18 km E Kabul, 1,700 m, 25.vi.-3.vii.1966, H.G. Amsel leg. (SMNK). 10ð, 30 China, Shapotou, Zhongwei County, Ningxia Huizu Autonomous Region, 1,200 m, 10.viii.2000 (gen. prep. 181/07\$; 182/07 ) (NKUM); 1 ${ }^{2}$, China, Zhongwei, Ningxia Huizu Autonomous Region, 9.iv.1987, Guodong Ren leg. (gen. prep. L92034) (NKUM).

Diagnosis. This species most closely resembles $A$. kuznetzovi and $A$. deserta sp. n., but the white medial costal spot is rounded rather than elongate. The male genitalia differ slightly from those of $A$. deserta in the longer and narrower saccus and from those of $A$. kuznetzovi in the shorter and broader genitalic capsula. Agnippe conjugella differs from $A$. pseudolella in the forewing with narrowly connected rather than separated black spots on costal margin. The male genitalia differ slightly from those of $A$. pseudolella in the straight rather than weakly outwardly curving valva, slightly longer saccus and cucculus, and the aedeagus lacking a rounded plate. Moreover the genitalic capsula in A. conjugella is longer and narrower than in $A$. pseudolella. The female genitalia are characterized by having a short, anteriorly narrowed antrum, elongate signum and relatively long apophyses anteriores.

Adult (Figs 17, 18). Wingspan 7.5-8.7 mm. Head and labial palpus white. Segment 2 of labial palpus black at base. Scapus black, beneath off-white, other antennal segments white, ringed with brown basally. Tegula and thorax yellow-cream. Forewing with black or dark-brown basal patch, with two connected black spots: medial spot narrow, elongate; subapical spot usually larger than 
medial one, rounded or sub-triangular; medial sub-costal spot white; posterior half of forewing yellow-cream; apex black, usually separated from subapical spot by narrow white fascia, but sometimes both are connected; cilia light grey, black-tipped. Hindwing light grey.

Male genitalia (Figs 40, 64). Sternite VIII weakly constricted medially, distal portion gradually narrows. Uncus long and narrow, weakly broadened distally, apex rounded with small incision. Ventral part of gnathos narrow, gradually broadens in distal half, apex relatively narrow with long and slender medial and short, triangular lateral processes. Cucullus slender, wider distally, apex rounded with distinct horn, not reaching top of uncus. Sacculus elongate, digitate. Juxta lobes short, narrow. Saccus slender, apex rounded. Vesica with a few needleshaped cornuti. Variation: The males from China differ slightly in short, broad uncus and very small white medial costal spot.

Female genitalia (Figs 81, 82). Segment VIII elongate, trapezoid, distinctly longer than broad. Apophyses anteriores nearly as long as length of segment VIII, straight. Antrum short, funnel-shaped, sub-triangular, distinctly shorter than apophyses anteriores. Corpus bursae suboval, accessory bursae long and narrow, with row of small teeth. Signum cap-shaped, anterior margin irregularly dentate. Variation: Shape of antrum of female genitalia varies from sub-triangular to cylindrical, parallel-sided.

Biology. In the deserts of Uzbekistan, larvae feed on leaves of Alhagi sparsifolia (Fabaceae) held together by silk spun by the larvae. Larvae 5-6 mm, pale yellow, with two lateral and two dorsal rows of dark red spots; there are at least three generations from May to September; pupae overwinter (Falkovitsh \& Bidzilya, 2003: 116). Adults were collected at 1,700 $\mathrm{m}$ in Afghanistan.

Distribution. Afghanistan, N Iran, SE Kazakhstan, Uzbekistan, Turkmenistan, Kyrgyzstan, China: Ningxia.

Remarks. Agnippe haberlandi was described from a series of specimens of both sexes from Afghanistan. The holotype of this species is superficially similar to the lectotype of $A$. conjugella (see Figs 17,18 ). The male genitalia of $A$. haberlandi are indistinguishable from those of the lectotype of $A$. conjugella figured by Park (1996: Figs 15-17) The genitalia of both sexes of $A$. haberlandi are likewise identical to those of $A$. conjugella from other localities.

\section{Agnippe pseudolella (Christoph, 1888)}

Lita pseudolella Christoph, 1888. Lectotype ô, Russia, labelled "Sarepta, 5.vii.1867, Christoph" (gen. slide no. 28793), (BMNH), here designated [examined].

Phthorimaea pseudolella (Christoph, 1888): Gaede, 1937. Evippe pseudolella (Christoph, 1888): Park, 1996. Agnippe pseudolella (Christoph, 1888): Lee \& Brown, 2008. Lita cephalella Caradja, 1920 [synonymized by Park, 1996]. Lectotype đ, N. Kazakhstan, labelled "Uralsk, 4.vi.[19]07, M. Bartel” (slide no. Car. 3000, Povolný), (MGAB), designated by Popescu-Gorj (1992).

Type material. Lectotype of pseudolella as above.
Additional material. $1 \delta$, Turkey, Prov. Nevsehir, Zelve, 900 m, 21.vi.1996, Fritz Schepler leg. (gen. prep. 199/08) (ZMUC); 10 , N Iran, 1,650 m, road from Karaj (Keredj on label) to Chaloos (Chalus), Elburs Mts., 27.vi.1969, H.G. Amsel leg. (gen. prep. 166/07) (SMNK); 10, E Afghanistan, Pol-i-Charchi, 18 km E Kabul, 1,700 m, 25.vi.-3.vii.1966, H.G. Amsel leg. (gen. prep. 155/07) (SMNK); $2 \hat{0}$, Russia, Astrakhan Region, Baskunchak Lake, 7.v.2002, O. Pak leg. (gen. prep. 168/07) (ZMKU); 10․ Kazakhstan, $40 \mathrm{~km}$ S Zhana-Arka, Karaganda Region, 1.vi.1960, Kerzhner leg. (gen. prep. 177/07) (ZIN); 1 ex., Kazakhstan, station Akkum, 80 km NW Turkestana, 29.v.1966, Pastukhov leg. (ZIN); 10, Kazakhstan, Kokshetau Hills near Terisakkan River, 11.vii.1958, Falkovitsh leg. (ZIN); 2 q , Turkmenistan, Central Kopetdag, Germab, 780 m, 20.-22.vi.1982, Falkovitsh leg. (gen. prep. 169/07; 185/07) (ZIN); 10 , Turkmenistan, 22 km SE Ashkhabad, Kel'techinar River, 14.vi.1986, Falkovitsh leg. (ZIN); 1 \%, Turkmenistan, Kara-Kala, Ashkhabad Region, garden of Nat. Inst. of Plant Growing, at light, 10.viii.1952, Kuznetzov leg. (ZIN); 1 \%, Tajikistan, $30 \mathrm{~km}$ N Dushanbe, Kondara, 28.vi.1986, Puplesis leg. (ZIN); 1 ex., same locality, at light, 23.viii.1976, V. Kuznetzov leg. (ZIN). 10. China, Erdaoqiao, Ejin Qi, Inner Mongolia, $927 \mathrm{~m}$, 17.vii.2006, Xinpu Wang \& Xiangfeng Shi leg. (gen. prep. 200/07) (NKUM).

Diagnosis. This species is similar to $A$. conjugella, but differs externally in the interrupted black spots near costal margin of forewing. For separation from $A$. miniscula see under that species. The female genitalia differ from those of $A$. conjugella in the slightly longer antrum, shorter apophyses anteriores and rounded rather than subtriangular signum, and longer bursae appendix with large sub-triangular teeth. The male genitalia are most similar to those of $A$. conjugella, for separation see under that species.

Adult (Fig. 19). Wingspan 8.3-10.0 mm. Head and labial palpus white. Segment 2 of labial palpus cream at base. Scapus brown, beneath cream, other antennal segments white, ringed with brown basally. Tegula and thorax cream. Forewing with black basal patch and two black spots separated by white scales: medial spot from costal margin to half width, sub-apical spot from costal margin almost to posterior margin of forewing; posterior half of forewing yellow-cream; apex black; cilia grey, black-tipped. Hindwing light grey.

Male genitalia (Figs 41-43, 65, 66). Sternite VIII weakly constricted medially, distal portion gradually narrows. Uncus long and narrow, weakly broader distally, apex rounded with small incision. Ventral part of gnathos narrow, gradually broadens distally, apex broad with short processes. Cucullus slender, weakly curved and broader distally, apex rounded with distinct horn, reaching near top of uncus. Sacculus digitate, elongate. Juxta lobes short, narrow. Saccus slender, apex pointed. Vesica with several needle-shaped cornuti. Variation: The males from China are externally similar to A. pseudolella, but their genitalia (Fig. 43) are characterized by elongate, weakly basally constricted sacculus, which resembles that of $A$. conjugella.

Female genitalia (Fig. 83). Segment VIII trapezoid, slightly broader than long. Apophyses anteriores slightly longer than segment VIII, weakly curved. Antrum short, 
funnel-shaped, shorter than apophyses anteriores. Corpus bursae rounded; accessory bursae with row of relatively large, sub-triangular teeth. Signum rounded, anterior margin irregularly dentate or broadly rounded.

Biology. Host plant unknown. Adults fly from May to July at an altitude of $1,700 \mathrm{~m}$.

Distribution. Turkey; Russia: Volgograd Region, Astrakhan' Region; Kazakhstan; N Iran; Turkmenistan; Tajikistan; China: Inner Mongolia.

\section{Agnippe miniscula (Li, 1993)}

Evippe miniscula Li, 1993. Holotype + , China, labelled "Turfan, Xinjiang Uygur Autonomous Region, 120 m, 27.vii.1987, Li Houhun" (NKUM) [examined]. Agnippe miniscula (Li, 1993): Lee \& Brown, 2008.

Type material. Holotype of miniscula as above; $8 \hat{0}, 22 q$, paratypes of miniscula, same data as holotype (gen. prep. L92062 \%; L92063 $;$; 89140 \% 89287 ).

Diagnosis. A small species with strongly developed light brown pattern on forewing. Externally it resembles A. pseudolella, but differs in being smaller and having a yellow-brown rather than black apex of the forewing. The male genitalia differ slightly from those of $A$. pseudolella and $A$. conjugella in having a very small or reduced horn at the apex of cucullus and an apically curved aedeagus. It also differs from A. pseudolella in the narrower and longer genitalia capsula. Moreover, this species is characterized by the very narrow distal part of sternite VIII. The female genitalia resemble those of $A$. conjugella, but differ in the longer apophyses anteriores.

Adult (Fig. 20). Wingspan 6.0-8.0 mm. Head and labial palpus white. Segment 2 of labial palpus cream at base. Scapus brown, beneath cream, other antennal segments white, ringed with brown basally. Tegula and thorax cream. Forewing with light brown basal patch, with two brown spots separated by white scales: medial spot near costal margin to half width and subapical spot from costal margin almost to posterior margin; posterior half of forewing and sub-apical area yellow-cream; apex yellowish with diffused light brown spot at base of cilia; cilia light grey, brown tipped. Hindwing light grey.

Male genitalia (Figs 44, 67). Sternite VIII narrow, elongate, gradually narrowed distally. Uncus long and narrow, weakly broader distally, apex rounded with small incision. Ventral part of gnathos narrow, gradually broadens distally, apex broad with short processes. Cucullus slender, weakly widens distally, apex rounded, not reaching top of uncus. Sacculus relatively long, digitate. Juxta lobes short, narrow. Saccus long, slender, apex weakly pointed. Vesica with several needle-shaped cornuti.

Female genitalia (Figs 84, 85). Segment VIII elongate, distinctly longer than broad. Apophyses anteriores very long, straight. Antrum short, funnel-shaped, shorter than apophyses anteriores. Corpus bursae rounded; accessory bursae with row of small teeth. Signum narrow, elliptical.

Biology. Host plant unknown. Adults fly in June and July at an altitude of $1,320 \mathrm{~m}$.

Distribution. China: Xinjiang.

\section{Agnippe separatella sp. $\mathbf{n}$.}

Type material. Holotype + , labelled "S-Iran, $42 \mathrm{~km}$ wnw Djahrom, 1300 m, Astragalus steppe, 26.iii.1973, H. Amsel" (SMNK). Paratypes: $2 \hat{0}, 1$, , same data as holotype (gen. prep. 157/07 ${ }^{\circ}$ ) (SMNK); 10, 1 + , "S-Iran, 4.-7.vi.1969, Miyan Kotal, 1900 m, östl. Kazerun, 5140 ol./29 30 nB, H.G. Amsel leg." (gen. prep. 162/07 \%) (SMNK).

Diagnosis. This species can be easily recognized as the forewing has a well developed white pattern and brown medial costal spot. The male genitalia are characterized by the very long saccus, short cucullus, and very short and broad uncus. The female genitalia are most similar to those of $A$. conjugella and A. miniscula, but differ in the very short antrum.

Adult (Fig. 21). Wingspan 7.5-8.0 mm. Head, thorax, tegula and labial palpus white. Base of outer surface of segment 2 of labial palpus black. Scapus black, other antennal segments black, with narrow white basal rings. Forewing white with brown basal patch, triangular brown spot on middle of costal margin, apex brown; cilia darkgrey, black-tipped. Hindwing light grey.

Male genitalia (Figs 45, 68). Sternite VIII short, basal portion about twice broader than distal portion, apex rounded. Uncus very short and broad, apex rounded with small incision. Ventral part of gnathos gradually broadens towards the apex, apex broad with very short lateral and long medial processes. Cucullus short, weakly curved, apex terminates in a pointed horn, not reaching top of uncus. Sacculus long, digitate. Juxta lobes short, narrow. Saccus long, apex weakly pointed and broad. Vesica with a few needle-shaped cornuti.

Female genitalia (Fig. 86). Segment VIII distinctly broader than long. Apophyses anteriores slightly longer than segment VIII, straight. Antrum short, funnel-shaped, sub-triangular, shorter than apophyses anteriores. Corpus bursae rounded; accessory bursae short and narrow, with row of small teeth. Signum narrow, elliptical.

Biology. Host plant unknown. Adults were collected at the end of March and early in June at an altitude between 1300 and $1900 \mathrm{~m}$.

\section{Distribution. S Iran.}

Etymology. The specific name reflects its distinctive genitalia and external characters, and separate position within the genus (Latin: separatus - separate).

ACKNOWLEDGEMENTS. We wish to express our gratitude to R. Trusch (SMNK), S. Sinev, M. Falkovitsh (ZIN), K. Sattler $(\mathrm{BMNH})$, and O. Karsholt (ZMUC) for their assistance when working on these collections, valuable information and loan of material. The first author is very thankful for an Ernst Mayr Travel Grant, which enabled him to study the collections in SMNK and ZSM.

\section{REFERENCES}

Amsel H.G. 1961: Zwei neue Evippe-Arten aus Afghanistan, Iran und Nord-Syrien (Lepidoptera, Gelechiidae). Beitr. Naturk. Forsch. SW-Dt. 20: 99-103.

BeCKer V.O. 1984: 29. Gelechiidae. In Heppner J.B. (ed.): Atlas of Neotropical Lepidoptera. Checklist: Part 1. Micropterigoidea - Immoidea. Dr W. Junk Publishers, The Hague, pp. 44-53. 
CARAdJA A. 1920: Beitrag zur Kenntnis der geographischen Verbreitung der Mikrolepidopteren des palaearktischen Faunengebietes nebst Beschreibung neuer Formen. Dt. Entomol. Z., Iris 34: 75-179.

Chambers V.T. 1872: Micro-Lepidoptera. Can. Entomol. 4: $146-150$.

Chambers V.T. 1873: Micro-Lepidoptera. Can. Entomol. 5: 185-190.

Chambers V.T. 1875: Tineina from Texas. Can. Entomol. 7 : $105-108$

Chambers V.T. 1880: Description of some new Tineina, with notes on a few old species. J. Cincinnati Soc. Nat. Hist. 2: 179-194.

Christoph H. 1888: Diagnosen zu einigen neuen Lepidopteren des palaearctischen Faunengebietes. Hor. Soc. Entomol. Ross. 22: $308-314$.

Clarke J.F.G. 1955: Catalogue of the Type Specimens of Microlepidoptera in the British Museum (Natural History) Described by Edward Meyrick. Vol. 1. Trustees Brit. Mus., London, $332 \mathrm{pp}$.

Clarke J.F.G. 1969: Catalogue of the Type Specimens of Microlepidoptera in the British Museum (Natural History) Described by Edward Meyrick. Vol. 7. Trustees Brit. Mus. London, $531 \mathrm{pp}$.

Falkovitsh M.I. \& Bidzilya O.V. 2003: Gelechiidae (Lepidoptera) reared from the larvae collected in Kyzylkum desert, with description of new species. Proc. Zool. Mus. Kiev Taras Shevchenko Nat. Univ. 1(1): 113-147 [in Russian, English abstr.].

FALKovitsh M.I. \& BidzILYA O.V. 2009: A list of gelechiid moths (Lepidoptera, Gelechiidae) of the Southern Kyzylkum. Proc. Zool. Mus. Kiev Taras Shevchenko Nat. Univ. 5: 65-98 [in Russian, English abstr.].

GaEde M. 1937: Gelechiidae. In Bryk F. (ed.): Lepidopterorum Catalogus 79. Dr. W. Junk Publishers, s'-Gravenhage, 630 pp.

HuEMER P. 1988: A taxonomic revision of Caryocolum (Lepidoptera, Gelechiidae). Bull. Brit. Mus. (Nat. Hist.) (Entomol.) 57: 439-571.

Huemer P. \& Karsholt O. 1999: Gelechiidae I (Gelechiinae: Teleiodini, Gelechiini). In Huemer P., Karsholt O. \& Lyneborg L. (eds): Microlepidoptera of Europe. Vol. 3. Apollo Books, Stenstrup, $356 \mathrm{pp}$.

LeE S. \& Brown R.L. 2008: Revision of Holarctic Teleiodini (Lepidoptera: Gelechiidae). Zootaxa 1818: 1-55.

Li H. 1993: A study of the Chinese Evippe Chambers (Lepidoptera: Gelechiidae). Entomotaxonomia 15: 208-218 [in Chinese, English abstr.].

Li H. 2002: The Gelechiidae of China (I) (Lepidoptera: Gelechioidea). Nankai University Press, Tianjin, 538 pp. [in Chinese, English abstr.].
Li H. \& Zheng L. 1998: Phylogeny and zoogeography of the Palaearctic Evippe (Lepidoptera, Gelechiidae). Acta Zootaxon. Sin. 23: 199-206 [in Chinese, English abstr.].

Lvovsky A.L. \& PIskunov V.I. 1989: The gelechiid moths (Lepidoptera, Gelechiidae) of the Transaltai Gobi. Nasekomye Mongolii 10. Nauka, Leningrad, pp. 521-571 [in Russian, English abstr.].

MeYrick E. 1917: Descriptions of South American Microlepidoptera. Trans. R. Entomol. Soc. Lond. 1917: 1-52.

MeYrick E. 1925: Lepidoptera Heterocera. In Wytsman P. (ed.): Genera Insectorum. Fasc. 184. V. Verteneuil \& L. Desmet, Tervuren, Bruxelles, $290 \mathrm{pp}$.

Meyrick E. 1936-1937: Exotic Microlepidoptera. Vol. 5. Taylor $\&$ Francis, Marlborough, $160 \mathrm{pp}$.

Mosher E. 1916: A classification of the Lepidoptera based on characters of the pupa. Bull. Illinois St. Lab. Nat. Hist. 12: 17-159, pls 19-27.

OKada M. 1961: The genera Evippe and Stenolechia of Japan, with the descriptions of two species of the latter (Lepidoptera: Gelechiidae). Trans. Shikoku Entomol. Soc. 7: 41-48.

PARK K.T. 1996: Illustrations and discussions on type-specimens of Gelechiidae (Lepidoptera) described by A. Caradja. Insecta Koreana 13: 59-75.

PitKIN L.M. 1986: A technique for the preparation of complex male genitalia in Microlepidoptera. Entomol. Gaz. 37: 173-179.

Ponomarenko M.G. 2005: Gelechiid moths (Lepidoptera, Gelechiidae) of the Palaearctics: functional morphology, male genitalia, phylogeny and taxonomy. In Sinev S.Yu. (ed.): Chteniya pamyati N.A. Kholodkovskogo 58 (1). Russian Entomological Society \& Zoological Institute, St. Petersburg, pp. 3-139 [in Russian, English abstr.].

PopesCu-GoRJ A. 1992: Le catalogue des types de lépidoptères gardés dans les collections du muséum d'histoire naturelle "Grigore Antipa" (Bucarest) (Fam. Micropterigidae - Pterophoridae). Trav. Mus. Hist. Nat. "Grigore Antipa" 32: 131-184.

Rebel H. 1941: Über einige neue Mikrolepidopteren von der Balkanhalbinsel und besonderes aus der Gegend des OchridaSees in Mazedonien. Izv. Tsarsk. Prirodonauch. Inst. Sofia 14: $1-8$.

SNellen P. 1884: Nieuwe of weinig bekende Microlepidoptera van Noord-Azie. Tijdschr. Entomol. 27: 151-186.

WANG S. \& Li H. 1994: A new species of Evippe Chambers and a new record of Anchinia Hübner from China (Lepidoptera: Gelechiidae, Oecophoridae). Entomol. Res. 1: 83-86, figs $1-5$.

Received October 15, 2009; revised and accepted December 2, 2009 